\title{
Mechanistic Studies of Homo- and Heterodinuclear Zinc Phosphoesterase Mimics: What Has Been Learned?
}

\author{
Andrea Erxleben* \\ School of Chemistry, National University of Ireland Galway, Galway, Ireland
}

Phosphoesterases hydrolyze the phosphorus oxygen bond of phosphomono-, di- or triesters and are involved in various important biological processes. Carboxylate and/or hydroxido-bridged dizinc(II) sites are a widespread structural motif in this enzyme class. Much effort has been invested to unravel the mechanistic features that provide the enormous rate accelerations observed for enzymatic phosphate ester hydrolysis and much has been learned by using simple low-molecular-weight model systems for

OPEN ACCESS

Edited by:

Federico Cesano,

University of Turin, Italy

Reviewed by:

Ebbe Nordlander

Lund University, Sweden

Salah S. Massoud

University of Louisiana at Lafayette,

United States

Annika Eisenschmidt,

University of Cambridge,

United Kingdom

*Correspondence:

Andrea Erxleben

andrea.erxleben@nuigalway.ie

Specialty section:

This article was submitted to

Inorganic Chemistry,

a section of the journal

Frontiers in Chemistry

Received: 26 October 2018

Accepted: 30 January 2019

Published: 21 February 2019

Citation:

Erxleben A (2019) Mechanistic Studies of Homo- and Heterodinuclear Zinc

Phosphoesterase Mimics: What Has

Been Learned? Front. Chem. 7:82.

doi: 10.3389/fchem.2019.00082 the biological dizinc(II) sites. This review summarizes the knowledge and mechanistic understanding of phosphoesterases that has been gained from biomimetic dizinc(II) complexes, showing the power as well as the limitations of model studies.

Keywords: zinc, hydrolysis (esters), phosphatase, biomimicry, catalysis

\section{INTRODUCTION}

The hydrolytic cleavage of phosphate esters is an important biochemical reaction in living systems, playing a fundamental role in energy metabolism (Berg et al., 2010), DNA repair (Cowan, 1998), RNA splicing (Kuimelis and McLaughlin, 1998), and signaling (Berg et al., 2010). It is relevant to the breaking down of bone material by osteoclasts (bone resorbing cells) in mammals and to the absorption and mobilization of phosphorus in plants (Cashikar et al., 1997; Oddie et al., 2000; Cleland and Hengge, 2006; Mitić et al., 2006; Schenk et al., 2013; Daumann et al., 2014). In certain bacteria phosphotriesterases have evolved that can hydrolyze organophosphates including insecticides and chemical warfare agents (Donarski et al., 1989; Dumas et al., 1990).

Under physiological conditions, phosphate esters are highly resistant toward hydrolysis (Cleland and Hengge, 2006). The half-life of a phosphodiester bond in the backbone of DNA has been estimated to be on the order of hundreds to thousands of millions of years (Williams et al., 1999; Schroeder et al., 2006). Yet DNAses can cleave DNA within seconds to minutes (Cowan, 1998). The majority of enzymes that catalyze phosphate ester hydrolysis contain two or more metal ions in their active site. $\mathrm{Zn}^{2+}$, which is a strong Lewis acid, labile and not redox active, is ideally suited for biological hydrolysis reactions. The use of metal complexes that mimic the structure and function of a metalloenzyme is a well-established approach in bioinorganic chemistry to develop highly effective catalysts modeled after nature and to gain a molecular level understanding of the enzymatic mechanism. In the late 1970s and 1980s pioneering work by the groups of Sargeson (Anderson et al., 1977; Jones et al., 1983; Hendry and Sargeson, 1989), Breslow (Gellman et al., 1986; Breslow et al., 1989), and Chin (Chin, 1991) among others gave the first insight into the role of the metal ion(s) in the mechanisms of phosphoester hydrolysis by metallohydrolases. 
Using phosphate esters with good leaving groups and kinetically inert mononuclear $\mathrm{Co}$ (III) complexes, metal-catalyzed hydrolysis reactions were shown to proceed through the following mechanisms: (i) Lewis acid activation, in which the metal polarizes the $\mathrm{P}-\mathrm{O}$ bond and activates the phosphorus for nucleophilic attack (Figure 1A); (ii) metal hydroxide activation, in which the metal generates (metal-bound) hydroxide to act as an efficient nucleophile at $\mathrm{pH} 7$ or as a general base (Figures 1B,C); (iii) stabilization of the leaving group (Figure 1D); and (iv) combinations of (i), (ii), and (iii). Mechanistic information was obtained through detailed kinetic studies including the measurement of rate-pH profiles and kinetic isotope effects. The rate accelerations achieved by the different activation modes could be quantified (Williams et al., 1999). Kimura and coworkers used macrocyclic dinuclear Zn(II) complexes to study the relationship between the number and type of donor atoms and the catalytic efficiency (Koike and Kimura, 1991). Later, the work was extended to dinuclear complexes that model the cooperativity of the metal ions in bimetallic hydrolases and to metal complexes, with pendant functional groups to mimic secondary interactions between the substrate and amino acid side chains in the active site of metalloenzymes (Young and Chin, 1995; Kimura, 2000; Daumann et al., 2014). A lot of what has been learned through the early studies has informed the rational design of highly efficient catalysts, often with non-biological metals such as lanthanides (Franklin, 2001; Liu and Wang, 2009). Metal complex-based hydrolysis catalysts have been discussed in several excellent review articles (Franklin, 2001; Mancin and Tecilla, 2007; Liu and Wang, 2009; Desbouis et al., 2012; Yu and Cowan, 2018).

The increasing role of computational chemistry has led to a renewed interest in mechanistic questions and a significant number of theoretical and combined theoretical and experimental studies have been published that investigated the mechanistic pathways in detail. This review intends to give a concise account of the contribution of experimental and computational studies of dinuclear biomimetic zinc(II) complexes to our current understanding of the mechanistic details of enzymatic phosphate ester hydrolysis with a focus on the recent literature.

\section{PHOSPHOMONOESTER HYDROLYSIS}

The half-life for the spontaneous hydrolysis of dianionic phosphomonoesters, $\operatorname{ROP}(\mathrm{O})_{3}^{2-}$,

$$
\mathrm{ROP}(\mathrm{O})_{3}^{2-}+\mathrm{H}_{2} \mathrm{O} \rightarrow \mathrm{HPO}_{4}^{2-}+\mathrm{ROH}
$$

is on the order of $10^{12}$ years at ambient temperature (Lad et al., 2002). In principle the reaction can proceed through different mechanisms; a dissociative mechanism involving a $\mathrm{PO}_{3}^{-}$ intermediate $\left(D_{N}+A_{N}\right)$, an associative mechanism with a fivecoordinate phosphorane intermediate $\left(\mathrm{A}_{\mathrm{N}}+\mathrm{D}_{\mathrm{N}}\right)$ or a concerted mechanism $\left(A_{N} D_{N}\right)$ with an associative or dissociative transition state depending on the synchronicity of bond formation and departure of the leaving group.
In nature, the hydrolysis of phosphomonoesters is catalyzed by phosphomonoesterases such as alkaline phosphatase, purple acid phosphatase or inositol monophosphatase. The active site of alkaline phosphatase from E. coli contains two $\mathrm{Zn}^{2+}$ ions and $\mathrm{a} \mathrm{Mg}^{2+}$ ion (Le Du et al., 2002). One of the phosphoryl oxygens is coordinated by the two $\mathrm{Zn}^{2+}$ ions, which also bind the nucleophile, a deprotonated serine, and the leaving group, respectively (Figure 2A). Experimental and theoretical data agree with a dissociative mechanism (Zalatan et al., 2007; López-Canut et al., 2009). Probably the best studied phosphomonoesterases are purple acid phosphatases (PAPs). PAPs are non-specific hydrolases that cleave a variety of phosphate esters and anhydrides at acidic $\mathrm{pH}$. They contain a heterodinuclear Fe(III)$\mathrm{M}$ (II) site and their characteristic purple color is due to a tyrosinate-to-Fe(III) ligand-to-metal charge transfer at about $560 \mathrm{~nm}$ (Mitić et al., 2006). The active site of red kidney bean PAP in which the divalent metal ion is $\mathrm{Zn}$ (II) (Sträter et al., 1995) is shown in Figure 2B. Although the sequence homology between PAPs from different sources is low, the seven amino acids that constitute the primary coordination sphere of the Fe(III)-M(II) core are conserved in all PAPs. The mechanism proposed by Klabunde et al. involves the monodentate coordination of the phosphate ester to the divalent metal ion followed by nucleophilic attack by Fe(III)-bound hydroxide (Klabunde et al., 1996). The strong Lewis acidity of $\mathrm{Fe}(\mathrm{III})$ allows the formation of $\mathrm{Fe}(\mathrm{III})$ $\mathrm{OH}$ at acidic $\mathrm{pH}$. For sweet potato PAP an alternative mechanism with bridging phosphate ester coordination and nucleophilic attack by a $\mu$-(hydr)oxide was suggested (Schenk et al., 2005). $\mathrm{Ga}(\mathrm{III})$ can replace $\mathrm{Fe}(\mathrm{III})$ in the active site and studies indicated that PAPs can switch between the two mechanisms depending on the metal ion composition/availability/solubility, the second coordination sphere, the actual substrate, and the $\mathrm{pH}$ value ("one enzyme-two mechanisms" hypothesis; Mitić et al., 2006; Smith et al., 2007). While a bridging oxide would be an efficient nucleophile, the nucleophilicity of a hydroxide that is tightly bound to two metals should be rather low. It was therefore suggested that the bridging hydroxide in hydrolytic enzymes shifts to a (pseudo-)terminal position on binding of the substrate (Bennett and Holz, 1997; Wang et al., 1999). Computational evidence for such a $\mu-\mathrm{OH}$ shift was seen in model systems for phosphodiesterases and will be discussed in the next section.

In contrast to the large number of studies on the catalysis of phosphodiester hydrolysis, the cleavage mechanism of phosphomonoesters by biomimetic zinc(II) complexes is little investigated (Anbu et al., 2012; Zhang et al., 2014a,c; Sanyal et al., 2015). In recent years, various studies have been aimed at elucidating the role of the heterodimetallic Fe(III)- $\mathrm{Zn}$ (II) site in PAP. However, the substrate employed is generally the phosphodiester bis (2,4-dinitrophenyl) phosphate (BDNPP), a widely used model for the phosphodiester linkages in DNA. Heterodinuclear Fe(III)-Zn(II) biomimetics that mostly do not show monophosphatase activity will therefore be discussed in the section on phosphodiester hydrolysis.

Phosphomonoester hydrolysis by dizinc(II) complexes is usually studied using 4-nitrophenyl phosphate as an ester with a good leaving group (NPP, Figure 3). The mechanism of the hydrolysis of the $\mathrm{NPP}^{2-}$ dianion is generally believed 

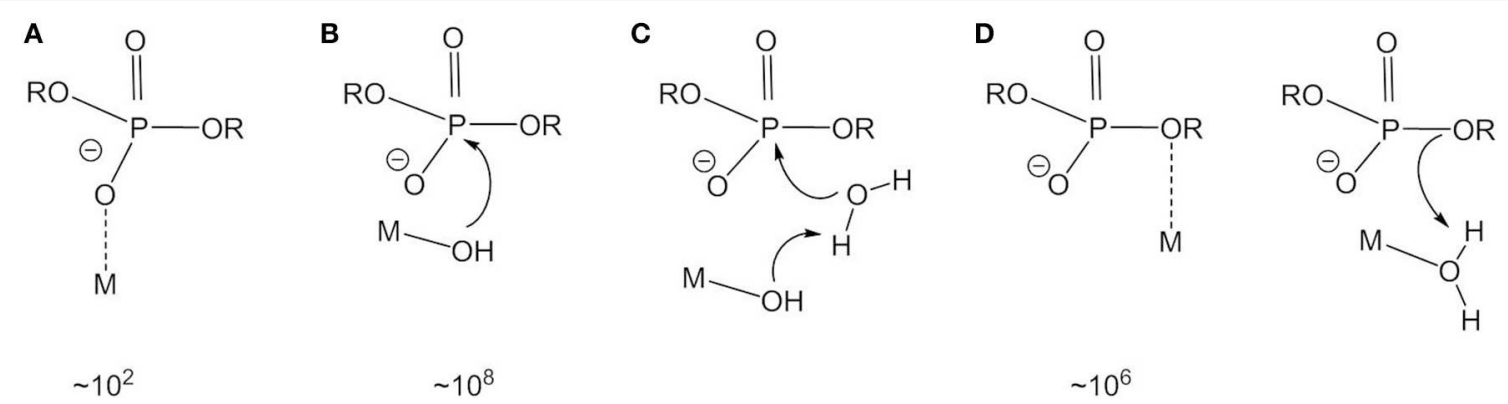

FIGURE 1 | Activation modes and rate accelerations for metal-catalyzed phosphate ester hydrolysis. (A) Lewis acid activation. (B) Nucleophile activation. (C) Base catalysis. (D) Leaving group stabilization.

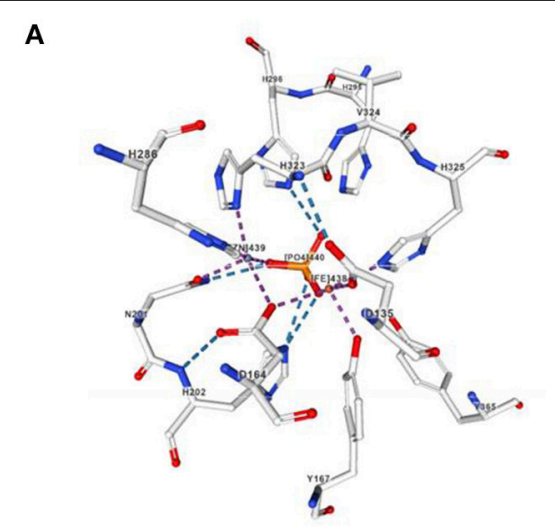

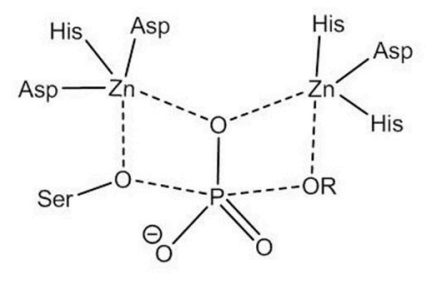
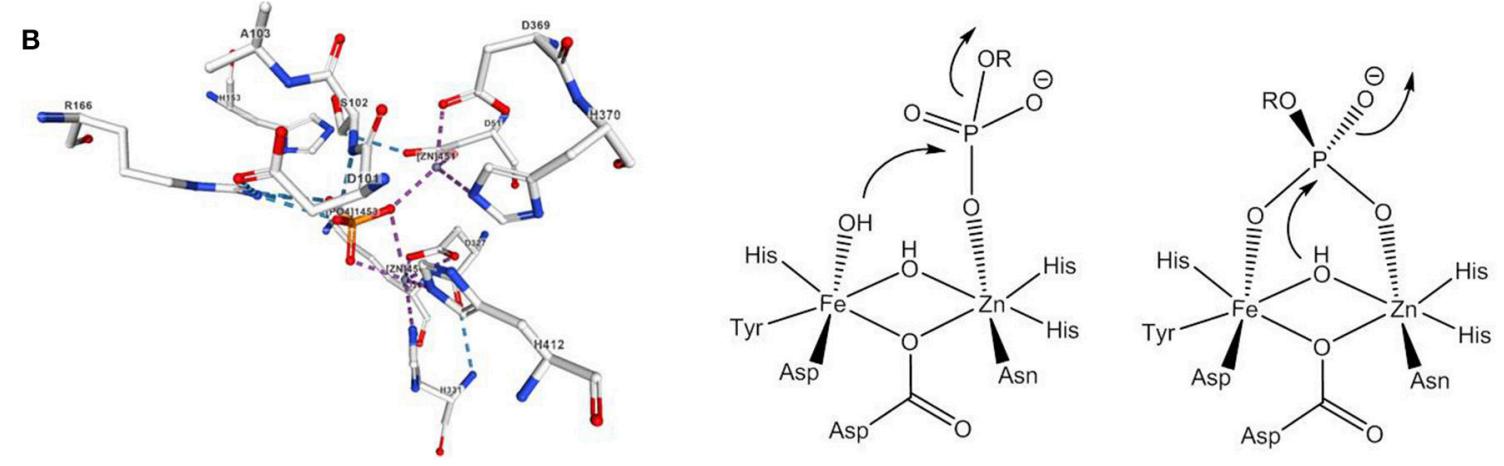

FIGURE 2 | Active site and mechanism(s) of (A) E. coli alkaline phosphatase and (B) red kidney bean PAP. The image of the dizinc(II) site complex with phosphate in (A) was created with the PDB $1 \mathrm{KHL}$ and associated publication (Le Du et al., 2002). The image of the active site complex with phosphate in (B) was created with the PDB 4KBP and associated publication (Klabunde et al., 1996). NGL Viewer (Rose et al., 2018) and RCSB PDB.

to be concerted with a loose transition state, while for phosphomonoester monoanions a dissociative mechanism involving metaphosphate as the intermediate has not been ruled out (Cleland and Hengge, 2006; Klähn et al., 2006; Kamerlin and Wilkie, 2007; Zhang et al., 2014a,c; Sanyal et al., 2015). The dianion is less reactive than the monoanion due to the higher negative charge of the transition state.

Kandaswamy and coworkers synthesized dizinc(II) complexes with a series of dinucleating, oxyimine-based macrocyclic ligands (Anbu et al., 2012, Figure 3). The dizinc complex of the symmetric ligand $\mathbf{H}_{2} \mathbf{L} \mathbf{1}^{\mathrm{a}}$ that had the shortest
$\mathrm{Zn}(\mathrm{II}) \cdots \mathrm{Zn}$ (II) distance and the least distorted geometry hydrolyzed monoanionic $\mathrm{NPP}^{-}$with a higher $\mathrm{k}_{\mathrm{cat}}$ value than did the analogous complexes of unsymmetric $\mathbf{H}_{2} \mathbf{L} \mathbf{1}^{\mathrm{b}-\mathrm{f}}$. The reaction kinetics showed a change in the reaction order at higher complex concentrations. Zhao and coworkers carried out DFT calculations to investigate the reaction mechanism (Zhang et al., 2014a,c). Different competitive catalytic mechanisms were found, depending on the concentration of the complex. At high concentrations two dinuclear entities form a hydroxidobridged dimer that binds $\mathrm{NPP}^{-}$to give the catalyst-substrate complex. Substrate coordination to two dizinc(II) entities 


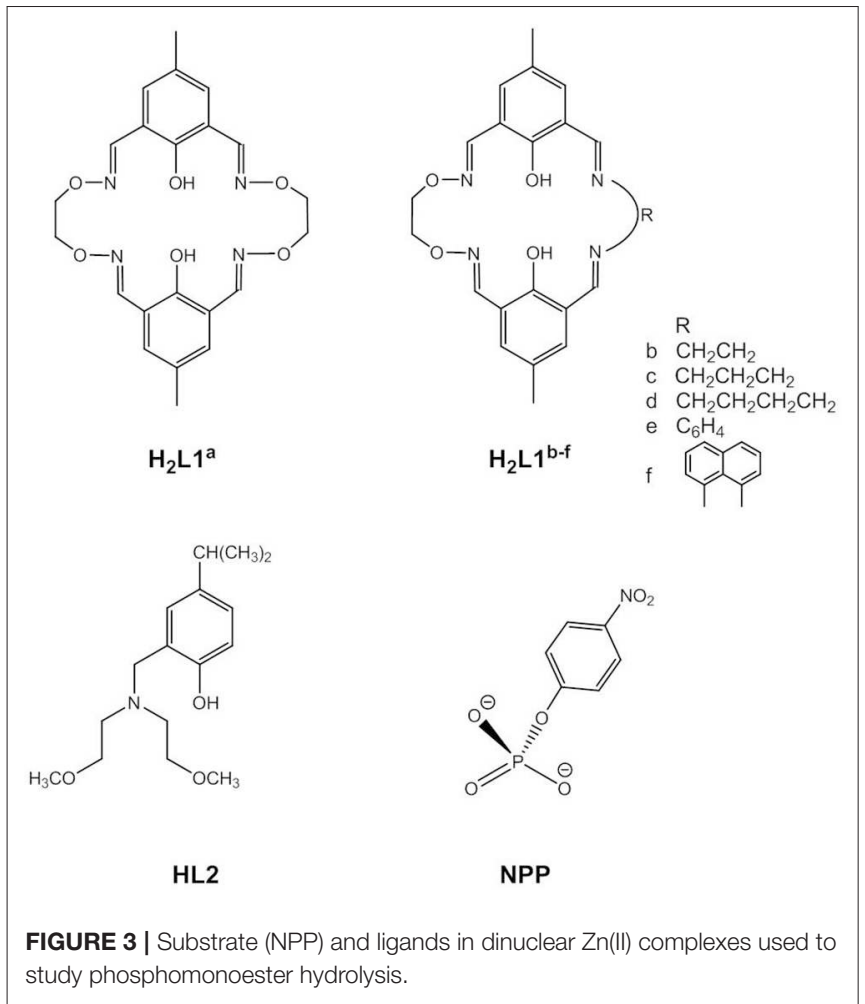

is also favored in the medium concentration range. More relevant to the enzymatic reaction, at low concentrations $\mathrm{NPP}^{-}$binds in a monodentate fashion to the catalytic species trans- $\left[\mathrm{Zn}_{2} \mathbf{L 1}^{\mathrm{a}}\left(\mathrm{H}_{2} \mathrm{O}\right)(\mathrm{OH})\right]^{+}$followed by nucleophilic attack by $\mathrm{Zn}-\mathrm{OH}$ to give a distorted trigonal bipyramidal phosphorane transition state (Figure 4). Substrate binding is stabilized by hydrogen bonding between the $\mathrm{P}-\mathrm{OH}$ proton and $\mathrm{Zn}-\mathrm{OH}$. Cleavage of the $\mathrm{P}-\mathrm{O}$ bond to the leaving group and protonation of the leaving group oxygen occur concurrently. In the case of unsymmetrical trans- $\left[\mathrm{Zn}_{2} \mathbf{L 1}^{\mathrm{f}}\left(\mathrm{H}_{2} \mathrm{O}\right)(\mathrm{OH})\right]^{+}$hydrogen bonding between $\mathrm{Zn}-\mathrm{OH}$ and $\mathrm{P}=\mathrm{O}$ and between $\mathrm{P}-\mathrm{OH}$ and $\mathrm{Zn}-\mathrm{OH}$ exists in the catalyst-substrate complex (Zhang et al., 2014c). Again, the theoretical calculations indicated a concerted mechanism involving simultaneous bond formation to the nucleophile and breaking of the bond to the leaving group in the transition state. The $\mathrm{P}-\mathrm{OH}$ proton forms a $\mathrm{H}$-bond with the leaving group oxygen in the transition state and proton transfer and $\mathrm{P}-\mathrm{O}$ bond cleavage are simultaneous. Modeling of a transition state with one phosphoryl atom coordinated to both $\mathrm{Zn}$ (II) centers of $\mathrm{ZnL1}^{\mathrm{f}}$ and one $\mathrm{Zn}$ (II) additionally binding to the leaving group oxygen demonstrated that metal-induced leaving group activation is less favorable than proton transfer-assisted leaving group departure. In the calculated mechanisms $\mathrm{NPP}^{-}$binds to the $\mathrm{Zn}$ (II) in the imine site, while the $\mathrm{Zn}$ (II) in the oxyimine site provides the nucleophile. The authors argued that the more electronegative oxygen atoms next to the imine nitrogens strengthen the $\mathrm{Zn}-\mathrm{N}$ bonds and weaken the bond to the nucleophile. However, the X-ray structure of $\left[\mathrm{Zn}_{2} \mathbf{L 1}^{\mathrm{c}}\left(\mathrm{H}_{2} \mathrm{O}\right)_{2}\right]\left(\mathrm{ClO}_{4}\right)_{2} 3 \mathrm{H}_{2} \mathrm{O}$ revealed no significant differences in the $\mathrm{Zn}-\mathrm{N}$ and $\mathrm{Zn}-\mathrm{OH}_{2}$ bond lengths between both binding sites. Furthermore, other studies led to the opposite conclusion that electron-withdrawing substituents result in a stronger $\mathrm{M}-\mathrm{OH}$ bond and thus decrease the nucleophilicity of metal-bound hydroxide by increasing the Lewis acidity of the metal ion (Coleman et al., 2010).

In the 2:2 complexes $\left[\mathrm{Zn}_{2} \mathrm{L2}_{2} \mathrm{X}_{2}\right](\mathrm{X}=\mathrm{Cl}, \mathrm{Br}, \mathrm{I})$ two $\mathrm{Zn}(\mathrm{II}) \mathbf{L} 2$ entities are linked through two phenoxide bridges. Xray analysis revealed the expected trans orientation of the two halides and $\mathrm{Zn}(\mathrm{II}) \cdots \mathrm{Zn}(\mathrm{II})$ distances around $3.1 \AA$, i.e., close to the metal-metal distance in zinc hydrolases (Sanyal et al., 2015). The phosphatase activity toward $\mathrm{NPP}^{2-}$ was studied in aqueous DMF, although it is not clear if the dinuclear structure is retained in solution. Theoretical calculations were described in the same paper and suggested that the D-cis form of the dinuclear complex is slightly more catalytically favorable than the D-trans form. In contrast to the macrocyclic complexes, a concerted reaction mechanism involving bidentate coordination of the phosphomonoester to both $\mathrm{Zn}$ (II) was found to be most favorable. One of the phenoxide bridges is replaced with a hydroxide so that $\mathrm{Zn}$ retains the more stable five-coordinate geometry. This bridging hydroxide serves as the nucleophile as proposed for sweet potato PAP (Figure 2B).

\section{PHOSPHODIESTER HYDROLYSIS}

\section{Hydrolysis of DNA Model Substrates}

It is assumed that the uncatalyzed hydrolysis of phosphodiesters proceeds via a concerted mechanism with a loose transition state (Hengge, 2002). An example for a $\mathrm{Zn}$ (II) containing phosphodiesterase is P1 nuclease that cleaves single-stranded RNA and DNA into mononucleotides. P1 nuclease has a trimetallic active site; $\mathrm{Zn} 3$ binds to the phosphodiester group, while a hydroxide that bridges $\mathrm{Zn} 1$ and $\mathrm{Zn} 2$ at a distance of $3.2 \AA$ is believed to act as the nucleophile (Volbeda et al., 1991; Figure 5).

Many phosphodiesterase mimics have been designed with bridging acetate ligands and it is generally assumed that these are substituted by terminal and/or bridging hydroxide ligands in aqueous solution. It has also been shown that phosphodiesters can readily replace carboxylate ligands in dizinc(II) complexes (Daumann et al., 2013). The most popular models for the phosphodiester linkages in DNA are bis(2,4-dinitrophenyl) phosphate, BDNPP, and bis(4-nitrophenyl) phosphate, BNPP, (Figure 6) that are usually converted to 2,4-dinitrophenyl phosphate and 4-nitrophenyl phosphate without further hydrolysis of the respective monoester taking place.

Based on kinetic data, X-ray analysis of the complex cocrystallized with a phosphodiester and binding studies, the following mechanisms have been assigned to dinuclear zinc(II) catalysts; (i) monodentate coordination of the phosphodiester to one $\mathrm{Zn}$ (II) and nucleophilic attack by $\mathrm{OH}$ bound to the other Zn(II) (Bazzicalupi et al., 2004; Jarenmark et al., 2010; Pathak et al., 2018) or to the same Zn(II) (Massoud et al., 2016); (ii) nucleophilic attack by $\mathrm{Zn}-\mathrm{OH}$ on the bridging substrate (Bazzicalupi et al., 1997, 2004; Daumann et al., 2012, 2013; Brown et al., 2016) and (iii) nucleophilic attack of the bridging substrate by a bridging hydroxide (Das et al., 2014, 2018; Montagner et al., 2014; Daver et al., 2016). As discussed above, a shift of $\mu-\mathrm{OH}$ to a 


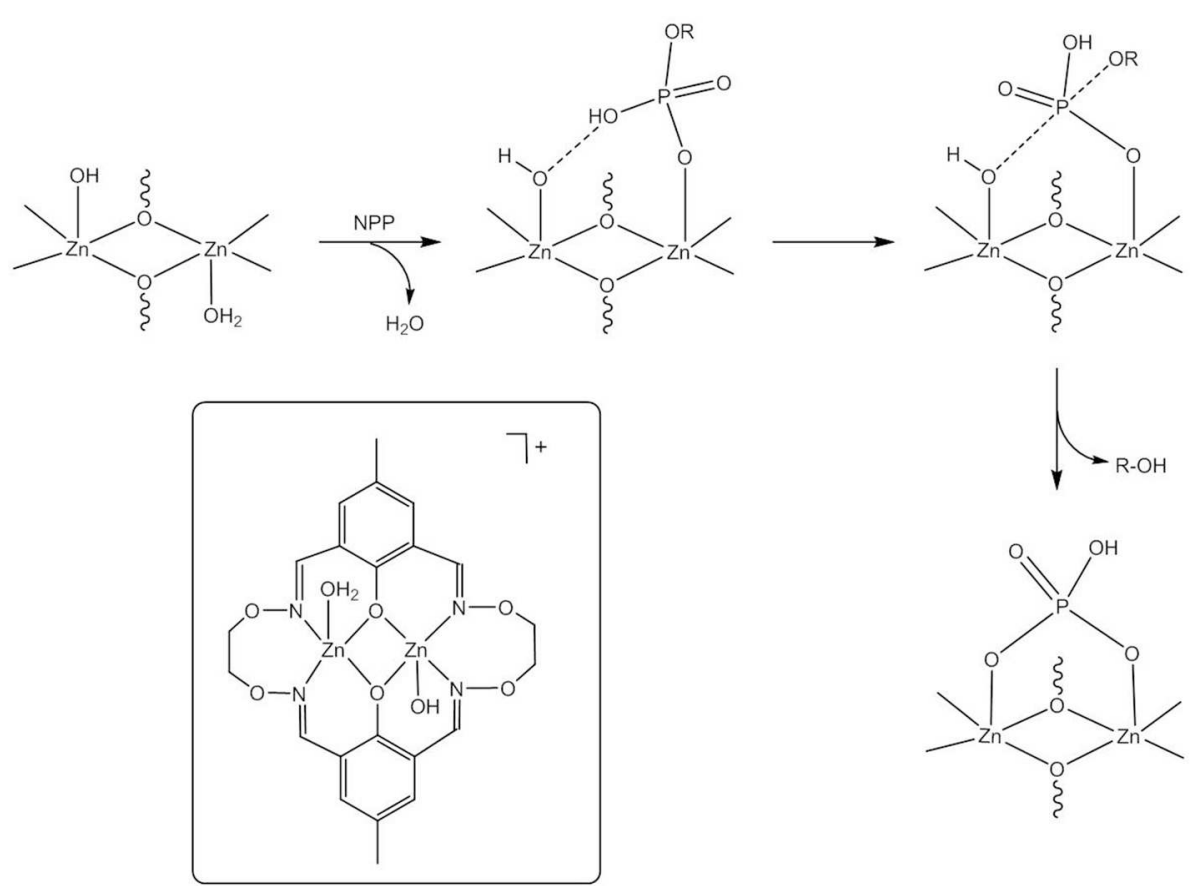

FIGURE 4 | Catalytic species and proposed mechanism for NPP- hydrolysis by the dizinc(II) complex of $\mathbf{H}_{\mathbf{2}} \mathbf{L 1}^{\mathrm{a}}$.

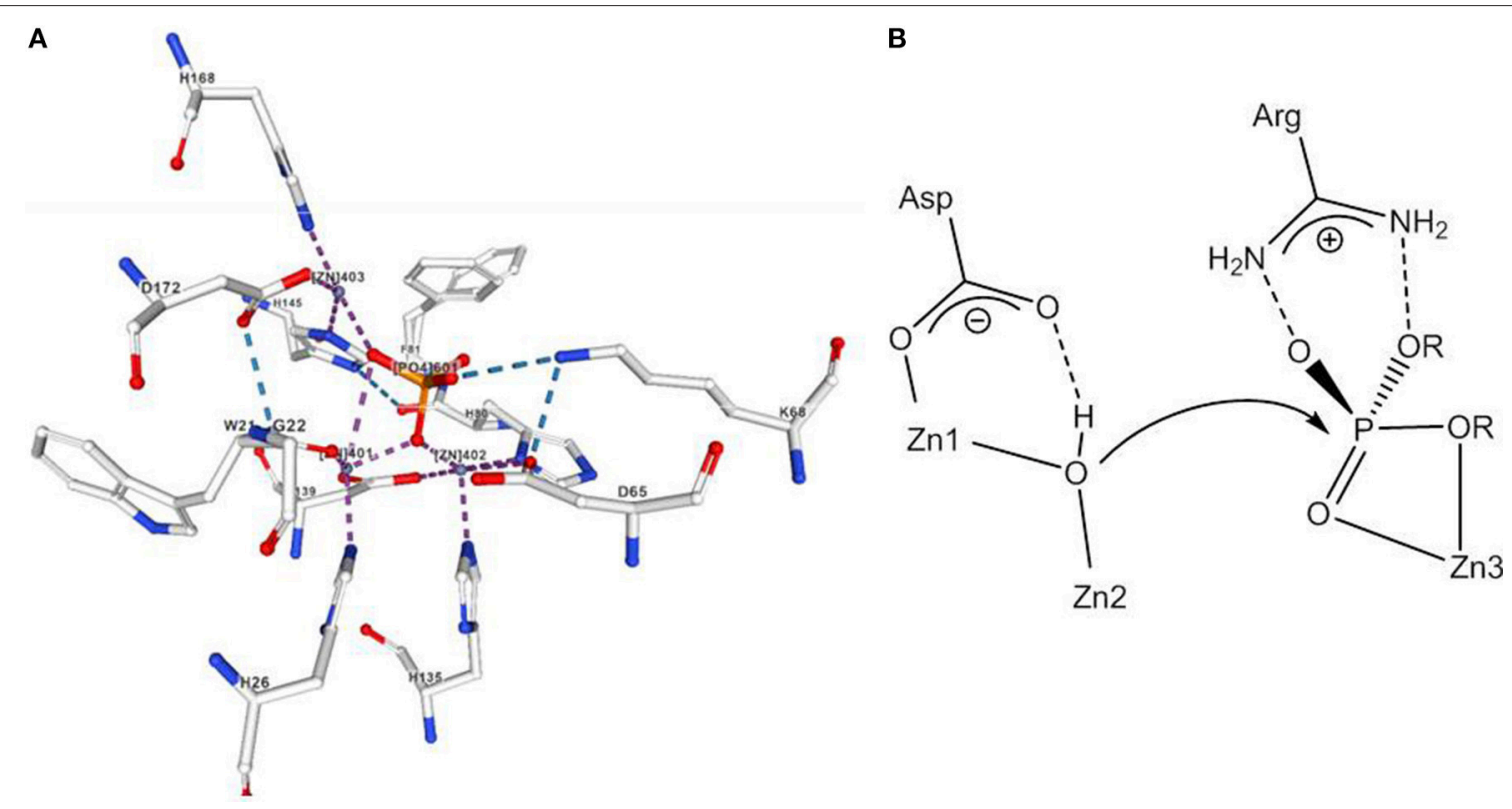

FIGURE 5 | (A) Active site of nuclease from Aspergillus oryzae with a coordinated phosphate. (B) Mechanism of phosphodiester hydrolysis catalyzed by P1 nuclease. The image in (A) was created with the PDB 5FBA and associated publication (Koval et al., 2016). NGL Viewer (Rose et al., 2018) and RCSB PDB.

terminal position in mechanism (iii) would render the attacking hydroxide a better nucleophile. Das et al. carried out DFT calculations on the hydrolysis of BDNPP by the unsymmetric dinuclear $\mathrm{Zn}(\mathrm{II})$ complex $\left[\mathrm{Zn}_{2} \mathbf{L} \mathbf{3}(\mu-\mathrm{OH})\right]^{+}$(Figure 7) which indicated that in the first step the phosphodiester binds to
$\mathrm{Zn} 1$ in the $\mathrm{N}_{3} \mathrm{O}_{2}$ site followed by a concerted step with a transition state in which $\mu-\mathrm{OH}$ is shifted toward $\mathrm{Zn} 1$ and the substrate adopts a bridging coordination mode (Das et al., 2014). DFT studies on the dizinc(II) complex of an analogous $\mathrm{N}_{5} \mathrm{O}_{2}$ ligand containing two 1-methylimidazole moieties (Das 

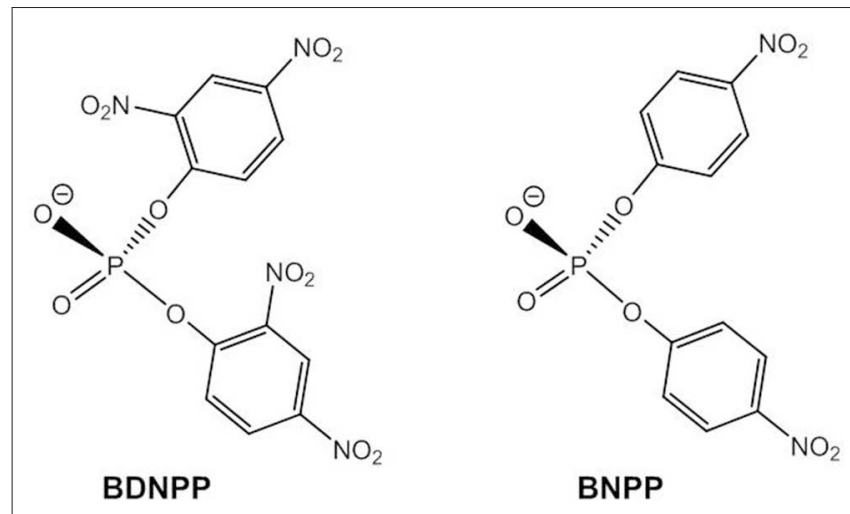

FIGURE 6 | Chemical structures of the DNA models BDNPP and BNPP.

et al., 2018) and on the related unsymmetric dizinc(II) complex $\left[\mathrm{Zn}_{2} \mathbf{L} 4(\mu-\mathrm{OH})(\mathrm{OH})\right]$ found the same mechanism (Daver et al., 2016). By contrast, DFT calculations of the hydrolysis of BNPP by trans- $\left[\mathrm{Zn}_{2}\left(\mathbf{L 1}^{\mathrm{a}}\right)\left(\mathrm{H}_{2} \mathrm{O}\right)(\mathrm{OH})\right]^{+}$suggested a stepwise mechanism involving nucleophilic attack by a terminally Zn-bound hydroxide and formation of the phosphorane intermediate as the rate-determining step (Zhang et al., 2014b). In the calculated mechanism bridging substrate binding also takes place in a stepwise manner with the phosphodiester binding initially via one phosphoryl oxygen to one $\mathrm{Zn}$ (II), followed by the formation of a second coordination bond between the nucleophile-binding $\mathrm{Zn}(\mathrm{II})$ and the other phosphoryl oxygen. This pathway appears to be favored over a concerted mechanism and over bridging $\mathrm{OH}$ acting as the nucleophile. It was noted that the macrocyclic ligand provides a rigid coordination sphere for the dizinc(II) site and imposes a relatively fixed $\mathrm{Zn}(\mathrm{II}) \cdots \mathrm{Zn}$ (II) distance of $3.047 \AA$, close to the distance between the two phosphoryl oxygens in a phosphodiester (ca. $2.7 \AA$ ), which of course should affect the preferred mechanistic pathway.

The ability to provide a (metal-bound) hydroxide at physiological $\mathrm{pH}$ value is obviously a key feature of metallophosphatases-or in fact of any hydrolytic metalloenzyme. Binding to two $\mathrm{Zn}^{2+}$ ions in dinuclear model systems can decrease the $\mathrm{pK}_{\mathrm{a}}$ of the $\mathrm{Zn}$-bound water to below 8 ; however, as discussed above, a bridging coordination mode of the hydroxide is detrimental to its nucleophilicity. Meyer and coworkers developed a class of highly preorganized pyrazolatebased dizinc(II) complexes that allowed the systematic variation of the $\mathrm{Zn}(\mathrm{II}) \cdots \mathrm{Zn}$ (II) distance (Bauer-Siebenlist et al., 2005; Meyer, 2006). By choosing the appropriate side arms, a large $\mathrm{Zn}(\mathrm{II}) \cdots \mathrm{Zn}$ (II) separation could be enforced that accommodated a $\mathrm{Zn}-(\mathrm{H}) \mathrm{O} \cdots \mathrm{HO}(\mathrm{H})-\mathrm{Zn}$ motif in which a $\mathrm{Zn}$-bound hydroxide is held by strong hydrogen bonding in an intramolecular $\mathrm{O}_{2} \mathrm{H}_{3}$ bridge (Figure 8). It was shown that the formation of the $\mathrm{Zn}-(\mathrm{H}) \mathrm{O} \cdots \mathrm{HO}(\mathrm{H})-\mathrm{Zn}$ unit brings about a similar decrease in the $\mathrm{pK}_{\mathrm{a}}$ of $\mathrm{Zn}-\mathrm{OH}_{2}$ to around the physiological $\mathrm{pH}$ as does the formation of the tightly bridged $\mathrm{Zn}-\left(\mu-\mathrm{OH}_{2}\right)-\mathrm{Zn}$ motif.

Another question addressed in model studies concerns the role of $\mathrm{Zn}$-alkoxide. In some metallohydrolases, alcohol moieties are involved in the enzymatic mechanism (Weston, 2005). An example is alkaline phosphatase, whose two $\mathrm{Zn}^{2+}$ ions bind a phosphate ester in a bridging mode which is then nucleophilically attacked by a serine alcoholate. In the next step the P-O bond of the phosphorylated serine intermediate is cleaved following nucleophilic attack by a Zn-bound hydroxide. Alkaline phosphatase catalyzes the hydrolysis of phosphomonoesters under basic conditions. However, model studies were carried out with BDNPP and are therefore discussed in this section. For mononuclear $\mathrm{Zn}$ (II) complexes it has been shown that a coordinated alcohol is a better nucleophile than a coordinated water (Koike et al., 1995; Xia et al., 2003; Livieri et al., 2004). On this basis, Chen et al. proposed a mechanism involving nucleophilic attack by a Zn-bound alcoholate for the reaction of $\left[\mathrm{Zn}_{2} \mathbf{H L 5}\right]^{2+}$, with BNPP giving a "transition complex" with the transesterification product covalently attached to the catalyst (Chen et al., 2005). However, the regeneration of the active site remained an open question. Daumann et al. studied the reaction in a $\mathrm{H}_{2}^{16} \mathrm{O} / \mathrm{H}_{2}^{18} \mathrm{O}$ /acetonitrile mixture (Daumann et al., 2012). The observation that ${ }^{18} \mathrm{O}$ was incorporated into the hydrolysis product demonstrated the participation of a $\mathrm{Zn}-\mathrm{OH}$ nucleophile and a reaction pathway analogous to that of alkaline phosphatase seems possible (Figure 9A). The dinucleating macrocycle HL6 containing an alcohol pendant was designed by Bazzicalupi et al. to model alkaline phosphatase (Bazzicalupi et al., 1999). The dizinc(II) complex contains a $\mathrm{Zn}-\mathrm{OR}$ and a $\mathrm{Zn}-\mathrm{OH}$ function and on the basis of ${ }^{31} \mathrm{P}$ NMR data and the characterization of the isolated BNPP cleavage product sequential nucelophilic attack by $\mathrm{Zn}-\mathrm{OR}$ and $\mathrm{Zn}-\mathrm{OH}$ was proposed (Figure 9B). The complex proved to have a higher reactivity than the parent complex lacking the pendant alcohol group, consistent with $\mathrm{Zn}$ OR presenting the better nucleophile. In contrast to the proposed mechanism for $\left[\mathrm{Zn}_{2} \mathrm{HL5}\right]^{2+}$, the P-O bond to 4-nitrophenolate is cleaved in the second step which is more in line with its better leaving group property compared to that of the ligand side arm. In other reported model complexes a Zn-bound alcohol group may also adopt the role of an acid catalyst and protonate the leaving group oxygen (Yashiro and Kawahara, 2004).

A DFT study of the cleavage of BDNPP by $\left[\mathrm{Zn}_{2} \mathbf{H}_{4} \mathbf{L} 7\left(\mathrm{OH}_{(2)}\right)\right]^{2+/ 3+}$ revealed a $10.6 \mathrm{kcal} \mathrm{mol}^{-1}$ higher energy barrier for alkoxide-mediated attack than for hydroxidemediated attack (Brown et al., 2016). Liu et al. observed a 93:7 ratio of hydrolysis to ethanolysis product of methyl(2-chlorophenyl) phosphate in the presence of $\left[\mathrm{Zn}_{2} \mathbf{L 8}\right]^{4+}$ when the reaction was carried out in ethanol containing 3.8 vol\% water (Liu et al., 2008a). A detailed analysis taking into account the ionization constant of water in ethanol and the kinetics of the reaction demonstrated that the catalytically active species is $\left[\mathrm{Zn}_{2} \mathbf{L 8}(\mu-\mathrm{OH})\right]^{3+}$ and confirmed the large selectivity for activating water as a nucleophile over ethanol. It is also noteworthy that this dizinc(II) complex provides an extremely high rate acceleration of 17 orders of magnitude over the background reaction in 96.2:3.8 ethanol/water (v/v) which is in the same order as the acceleration rates observed for highly efficient enzymatic phosphodiester hydrolysis. The contribution of a synergistic medium effect to this enormous rate enhancement will be discussed in the next section. The catalysis of the methanolysis of a series of methyl aryl phosphate 
<smiles>Cc1cc(CN(CC(=O)O)Cc2ccccn2)c(O)c(CN(Cc2ccccn2)Cc2ccccn2)c1</smiles>

$\mathrm{H}_{2} \mathrm{~L} 3$

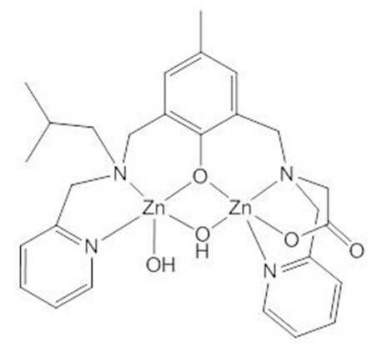

$\left[\mathrm{Zn}_{2} \mathrm{~L} 4(\mu-\mathrm{OH})(\mathrm{OH})\right]$<smiles>Cc1cc(CN(CCO)CCO)c(O)c(CN(CCO)CCO)c1</smiles>

$\mathrm{H}_{5} \mathrm{L7}$

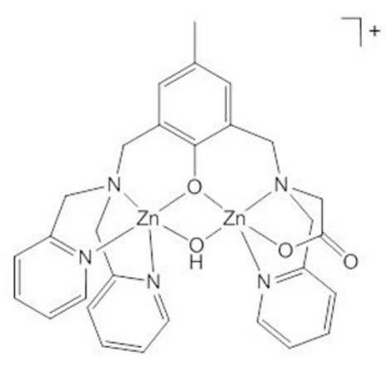

$\left[\mathrm{Zn}_{2} \mathrm{~L} 3(\mu-\mathrm{OH})\right]^{+}$<smiles>Cc1cc(CN(CCO)Cc2ccccn2)c(O)c(CN(CCO)Cc2ccccn2)c1</smiles>

$\mathrm{H}_{3} \mathrm{~L} 5$<smiles>C1CCN2CCCCNCCCN(CCCNCCCNC1)CNCCC2</smiles>

L8<smiles>Cc1cc(CN(CC(=O)O)Cc2ccccn2)c(O)c(CN(Cc2ccccn2)CC(C)C)c1</smiles>

$\mathrm{H}_{2} \mathrm{~L} 4$

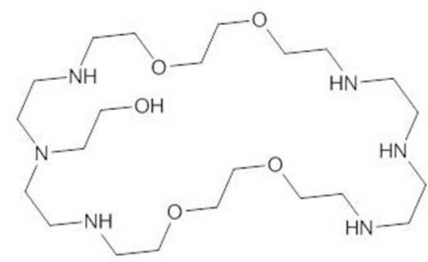

HL6

$\left[\mathrm{Zn}_{2} \mathrm{~L} 8(\mu-\mathrm{OH})\right]^{3+}$<smiles>Cc1cc(CN(Cc2ccccn2)Cc2cccc(NC(=O)CC(C)C)n2)c(O)c(CN(Cc2ccccn2)Cc2cccc(NC(=O)CC(C)C)n2)c1</smiles>

HL9<smiles>Cc1cc(CN(Cc2ccccn2)Cc2ccccn2)c(O)c(CN(Cc2cccc(NC(=O)C(C)(C)C)n2)Cc2cccc(NC(=O)C(C)(C)C)n2)c1</smiles><smiles>Cc1cc(CN(Cc2ccccn2)Cc2ccccn2)c(O)c(CN(Cc2ccccn2)Cc2cccc(N)n2)c1</smiles>

HL11<smiles>CCCCCCC(=O)Nc1cccc(CN(Cc2cccc(NC(=O)C(C)(C)C)n2)Cc2cc(C)cc(CN(Cc3ccccn3)Cc3ccccc3O)c2O)n1</smiles>

FIGURE 7 | Chemical structures of ligands $\mathbf{H}_{\mathbf{2}} \mathbf{L} \mathbf{3}-\mathbf{H}_{\mathbf{2}} \mathbf{L} \mathbf{1 2}$ and the dinuclear $\mathrm{Zn}(\mathrm{II})$ complexes $\left[\mathrm{Zn} \mathrm{n}_{2} \mathbf{L} \mathbf{3}(\mu-\mathrm{OH})\right]^{+},\left[\mathrm{Zn_{2 }} \mathbf{\mathbf { L }} \mathbf{4}(\mu-\mathrm{OH})(\mathrm{OH})\right]$, and $\left[\mathrm{Zn} \mathrm{n}_{2} \mathbf{L} \mathbf{8}(\mu-\mathrm{OH})\right]^{3+}$. 


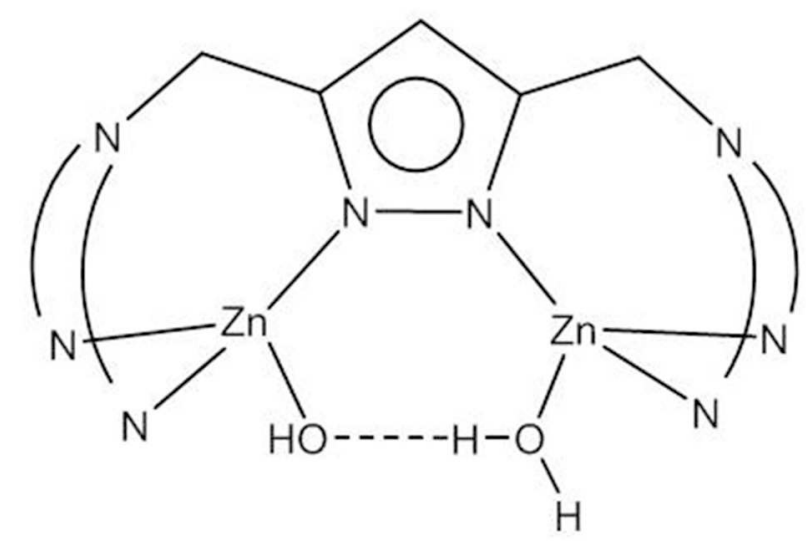

FIGURE 8 | Pyrazolate-bridged dizinc(II) complexes with the $\mathrm{Zn}-\mathrm{O}_{2} \mathrm{H}_{3}-\mathrm{Zn}$ motif.

diesters in methanol by the same complex was investigated and the kinetic data were found to be consistent with a two-step mechanism with rate-limiting formation of the phosphorane intermediate following nucleophilic attack of the bridging substrate by a monocoordinate Zn-methoxide (Neverov et al., 2008). Maxwell et al. reported DFT calculations on the $\left[\mathrm{Zn}_{2} \mathbf{L 8}\left(\mu-\mathrm{OCH}_{3}\right)\right]^{3+}$-mediated cleavage of 4-nitrophenyl methyl phosphate which gave three viable mechanisms with comparable energy barriers (Maxwell et al., 2013). In all three mechanisms the methoxide dissociates from one $\mathrm{Zn}(\mathrm{II})$ and nucleophilic attack on the bridging substrate and expulsion of the leaving group are concerted. The mechanisms differ in whether $\mu-\mathrm{OCH}_{3}$ acts as the nucleophile or as a general base by deprotonating an external $\mathrm{CH}_{3} \mathrm{OH}$ and in whether leaving group departure is assisted by direct metal-binding or via a metal-bound solvent molecule.

Bosch et al. investigated the role of the second coordination sphere and the influence of hydrogen bonding on substrate binding and catalytic activity (Bosch et al., 2014). The presence of amino and pivaloylamide substituents in ortho position to the pyridine nitrogen in $\mathbf{H L 9}-\mathbf{H}_{\mathbf{2}} \mathbf{L} \mathbf{1 2}$ led to lower MichaelisMenten constants and thus higher catalytic efficiencies for hydrolysing BDNPP compared to the unsubstituted complexes. The orientation of the substituents (symmetric substitution in HL9 vs. unsymmetric substitution in HL10) had a crucial influence on the shape of the rate-pH profile (sigmoidal vs. bell-shaped), the kinetic $\mathrm{pK}_{\mathrm{a}}$ value, the turnover number, and the maximum reaction rate. The authors also studied the effect of product inhibition and found that at high $\mathrm{pH}$, the dizinc(II) complex of HL9 formed a less stable product-catalyst complex than $\left[\mathbf{Z n}_{\mathbf{2}} \mathbf{L} \mathbf{1 1}\right]$, resulting in higher catalytic activity for the former.

For some of the active site mimics that hydrolyzed a DNA model substrate, the DNase activity was also evaluated using plasmid DNA. While there are examples for DNA cleavage activity (Peralta et al., 2010; Anbu et al., 2012; Montagner et al., 2014; Silva et al., 2017; Camargo et al., 2018), it is apparent that factors that are not important for simple phosphodiesters affect the hydrolysis of macromolecular DNA. Binding to a phosphodiester group in DNA can be sterically hindered by a bulky organic ligand (Massoud et al., 2016). On the other hand, metal complexes can show binding preferences for certain nucleotide sequences or structural motifs due to specific ligandDNA interactions (Camargo et al., 2018). Thus, model studies as those described in this section should not be seen predominantly as a predictive tool for developing efficient DNA cleavage agents, but as a means of studying the role of a dizinc(II) entity in the hydrolysis of the extremely stable phosphodiester linkages that form the backbone of DNA.

\section{Cleavage of RNA Dinucleotides and RNA Model Substrates}

Examples for biological RNA cleavage by a dimetallic site are ribozyme reactions (Steitz and Steitz, 1993) and HIV reverse transcriptase (Davies et al., 1991). RNA is more easily cleaved than DNA due to the $2^{\prime}-\mathrm{OH}$ group of the ribose ring which can act as an internal nucleophile. As shown in Figure 10, intramolecular attack on the phosphorus leads to the formation of a $2^{\prime}, 3^{\prime}$-cyclophosphate. Thus, RNA is not cleaved by hydrolysis but through transesterification. Whether this reaction proceeds by a stepwise mechanism via a pentacoordinated phosphorane intermediate or by a concerted mechanism via a pentacoordinated transition state has been debated. Evidence is now in favor of a two-step process in the case of the base-catalyzed reaction (Perreault and Anslyn, 1997; Oivanen et al., 1998; Lönnberg et al., 2004). At physiological pH the pentacoordinate phosphorane is monoanionic and relatively stable so that it can undergo pseudorotation. As a consequence, migration of the phosphodiester group to the $2^{\prime}$-position of the ribose ring can compete with RNA cleavage (Figure 10). In line with the principle of microscopic reversibility the leaving group has to depart from an axial position as the nucleophile attacks at an axial position. Under alkaline conditions the dianionic phosphorane is too short-lived and pseudorotation to an intermediate with the $3^{\prime}$-oxygen and a negatively charged oxygen in the axial positions is too energetically unfavorable for $3^{\prime}$ $\rightarrow \quad 2^{\prime}$ isomerization to occur. Experimental and computational data suggest that the reaction switches to a concerted pathway involving a dianionic pentacoordinate transition state, when the transesterification to the cyclophosphate is catalyzed by metal ions (Bunn et al., 2007; Humphry et al., 2008; Tsang et al., 2009; Edwards et al., 2010). Isomerization is not possible in this case.

2-Hydroxypropyl-p-nitrophenyl phosphate (HPNP, Figure 10) is a popular model for the phosphodiester linkages in RNA. The enhanced catalytic activity of various dinuclear zinc(II) complexes relative to their mononuclear analogs is usually attributable to double Lewis acid activation of HPNP adopting a bridging coordination mode. Like the catalysis of the hydrolysis of DNA models, HPNP transesterification is often more efficiently catalyzed by dizinc(II) complexes with unsymmetric ligands that have more available coordination sites to bind the substrate and water/hydroxide for base catalysis (Carlsson et al., 2004; Jarenmark et al., 2008). As the 2'-OH group is an internal, thus more efficient nucleophile, $\mathrm{Zn}-\mathrm{OH}$ does not 


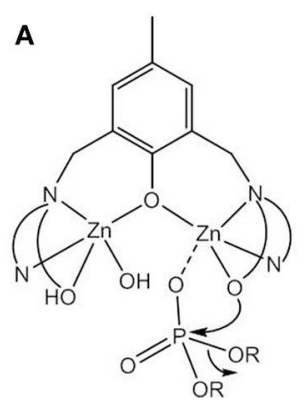

B

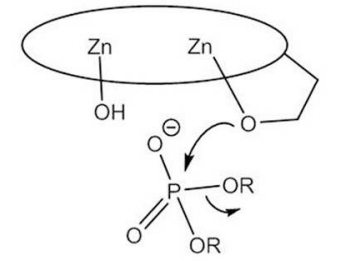

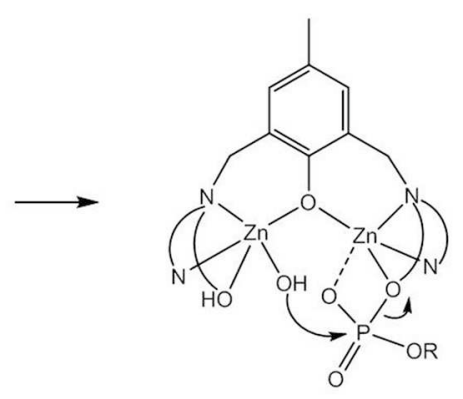

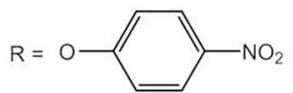

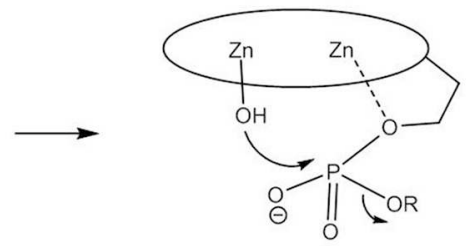

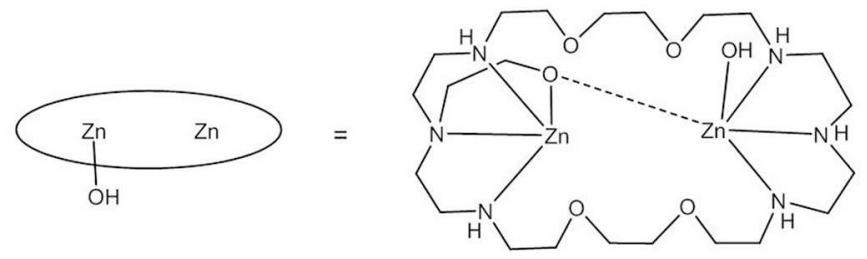

FIGURE 9 | Sequential involvement of a $\mathrm{Zn}-\mathrm{OR}$ and $\mathrm{Zn}-\mathrm{OH}$ nucleophile in the cleavage of BNPP by $\left[\mathrm{Zn}_{2} \mathbf{H L 5}\right]^{2+}(\mathbf{A})$ and $\left[\mathrm{Zn}{ }_{2} \mathbf{L 6}(\mathrm{OH})\right]^{2+}(\mathbf{B})$.

participate in the reaction mechanism as a nucleophile but serves as a base catalyst. Depending on the model complex and the solvent system, different conclusions were reached regarding the question of whether $\mathrm{Zn}-\mathrm{OH}$ acts as a general or a specific base catalyst. In general base catalysis, deprotonation of the $2^{\prime}$-OH group by $\mathrm{Zn}-\mathrm{OH}$ occurs concurrently with nucleophilic attack, while in specific base catalysis the 2'-oxyanion is formed in a pre-equilibrium step prior to rate-determining substrate cleavage.

The dinuclear $\mathrm{Zn}$ (II) complex of $\mathbf{L 8}$ is one of the most efficient RNA/HPNP cleavage catalysts reported to date. In methanol, in the presence of one equivalent $\mathrm{CH}_{3} \mathrm{O}^{-}\left[\mathrm{Zn}_{2} \mathbf{L 8}\right]^{4+}$ gives a $10^{8}$-fold rate acceleration of the cleavage of HPNP over the methoxide-catalyzed reaction (Neverov et al., 2006). Tsang et al. carried out a kinetic analysis of the transesterification of different 2-hydroxypropyl-aryl and alkyl esters by $\left[\mathrm{Zn}_{2} \mathbf{L 8}\left(\mathrm{OCH}_{3}\right)\right]^{3+}$ and found that the reaction proceeds through a transition state in which the departure of the leaving group has progressed to $45 \%$ (Tsang et al., 2009). A DFT study by Maxwell et al. revealed three plausible, competing mechanisms, all involving bridging substrate coordination (Maxwell et al., 2013): (i) direct nucleophilic attack by the metal-bound HPNP alkoxide concurrent with the cleavage of the leaving group bondthe departure of the leaving group is assisted by a terminally bound methanol acting as an $\mathrm{H}$ bond donor; (ii) rate-limiting nucleophilic attack through a general base mechanism leading to a phosphorane intermediate-subsequent bond cleavage is assisted by metal binding and (iii) nucleophilic attack through a general base mechanism and leaving group departure occurring in concert-the expulsion of the leaving group is assisted by hydrogen bonding with a terminally coordinated methanol. While experimental data were reported for the $\left[\mathrm{Zn}_{2} \mathbf{L 8}\left(\mathrm{OCH}_{3}\right)\right]^{3+}$-promoted transesterification of HPNP and 2hydroxypropyl-phenyl phosphate that are consistent with both a concerted and a stepwise mechanism, it has been argued that a stepwise pathway may be more likely because a strong electrostatic interaction between the highly charged dizinc(II) site and the putative dianionic phosphorane should stabilize the intermediate and the transition state leading to it (Bunn et al., 2007). Energetics calculations indicated that the transition state of the catalyzed reaction is stabilized by about -21 to $-23 \mathrm{kcal} \mathrm{mol}^{-1}$ relative to the transition state of the methoxide reaction. The charge of a phosphodiester increases from -1 to -2 when the catalyst-substrate complex proceeds to the transition state. It has been predicted that the coordination of two metal ions to a phosphate ester monoanion has the same effect as neutralizing it. It is believed that substrate binding to $\left[\mathrm{Zn}_{2} \mathbf{L 8}\left(\mathrm{OCH}_{3}\right)\right]^{3+}$ in alcoholic medium takes place in two steps (Bunn et al., 2007); The substrate binds initially as a monodentate ligand to one $\mathrm{Zn}^{2+}$ ion and then rearranges to the catalytically 


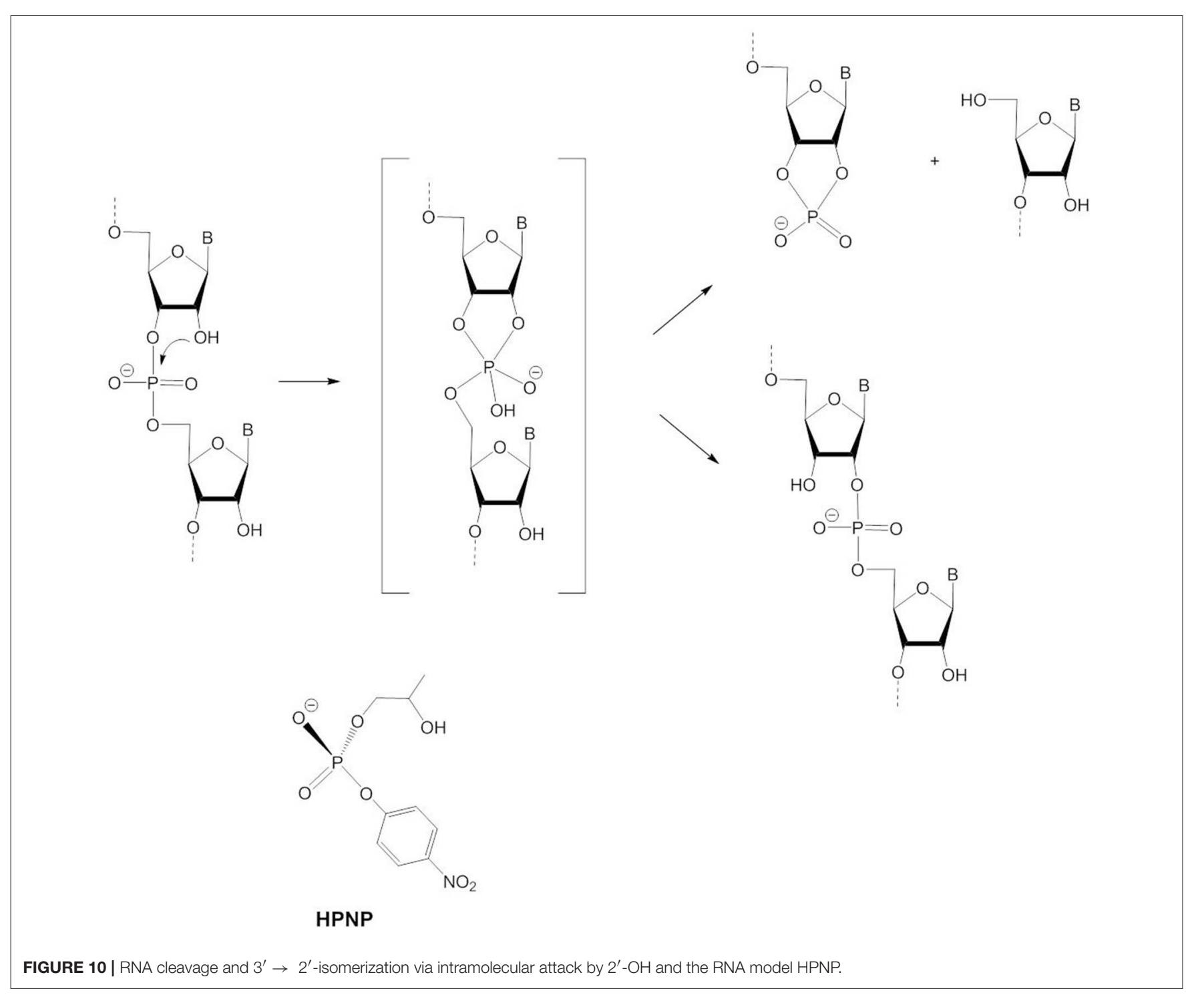

active species with a bridging coordination mode allowing double Lewis acid activation. For substrates with a good leaving group such as 4-nitrophenolate this rearrangement is rate-determining and the following steps of the transesterification reaction are fast. In the case of substrates with a poor leaving group complete equilibrium binding of the substrate occurs and the rate determining step is a chemical one that depends on the $\mathrm{pK}_{\mathrm{a}}$ value of the leaving group. Nucleophilic attack is ratedetermining when the $\mathrm{pK}_{\mathrm{a}}$ of the leaving group is lower than that of the nucleophile. When the leaving group $\mathrm{pK}_{\mathrm{a}}$ is greater, fission of the leaving group bond becomes rate-limiting. The change of the rate-determining step from formation to breakdown of the phosphorane intermediate manifests itself as a break in the Brønsted plot (plot of $\log \mathrm{k}_{\text {cat }}$ vs. leaving group $\mathrm{pK}_{\mathrm{a}}$ ) at the point where the effective $\mathrm{pK}_{\mathrm{a}}$ of the leaving group and the nucleophile are the same. For the transesterification in ethanol in the presence of $\left[\mathrm{Zn}_{2} \mathbf{L 8}\left(\mathrm{OC}_{2} \mathrm{H}_{5}\right)\right]^{3+}$, general-base catalyzed deprotonation of the $2^{\prime}-\mathrm{OH}$ group by $\mathrm{Zn}-\mathrm{OC}_{2} \mathrm{H}_{5}$ was proposed. Specific-base catalysis by an external ethoxide could be excluded, because the cleavage rate in ethanol exceeded the diffusion limit (Liu et al., 2008b). Support for concerted nucleophilic attack and loss of the leaving group comes from a study of the reaction of $\left[\mathrm{Zn}_{2} \mathbf{L 8}(\mathrm{OR})\right]^{3+}$ with a stable phosphonate analog of HPNP (Edwards et al., 2010). If the slow cleavage of 2-hydroxypropyl phenyl phosphonate were to proceed via a five-coordinate phosphorane intermediate, isomerization to 1-hydroxypropyl phenyl phosphonate should be observed, which was not the case.

In contrast to the general-base catalyzed cleavage of HPNP by $\left[\mathrm{Zn}_{2} \mathbf{L 8}\left(\mathrm{OC}_{2} \mathrm{H}_{5}\right)\right]^{3+}$ in ethanol, experimental data for the related dizinc(II) complex $\left[\mathrm{Zn}_{2} \mathbf{L 1 3}\left(\mathrm{OH}_{2}\right)\right]^{3+}$ (Figure 11) have been interpreted in terms of both general and specific base catalysis. Concerted nucleophilic attack and leaving group loss with specific-base catalysis in aqueous solution is now favored (Iranzo et al., 2003b; Yang et al., 2005; Humphry et al., 2008). Likewise, two conflicting computational studies were reported that came to different conclusions. DFT calculations that were most consistent 
<smiles>OC(CN1CCNCCNCC1)CN1CCNCCNC1</smiles>

HL13

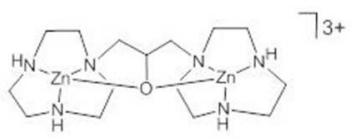

$\left[\mathrm{Zn}_{2} \mathrm{~L} 13\right]^{3+}$<smiles>c1ccc(CN(Cc2cccc(CN(Cc3ccccn3)Cc3ccccn3)c2)Cc2ccccn2)nc1</smiles>

L18<smiles>CCNCCCNCCCNCCCNCCCNCc1cc2cc(c1)NCCCNC2</smiles>

L20

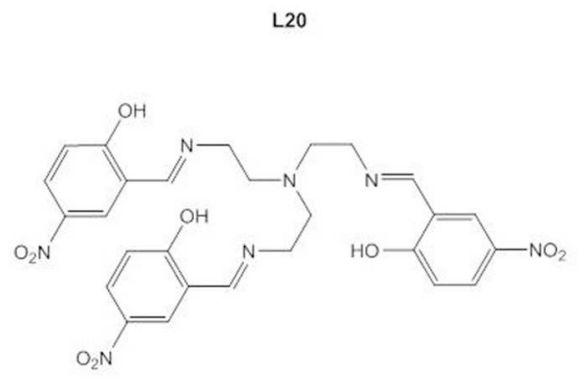

$\mathrm{H}_{3} \mathrm{~L} 23$<smiles>Nc1cccc(CN(Cc2cccc(N)n2)CC(O)CN(Cc2cccc(N)n2)Cc2cccc(N)n2)n1</smiles>

HL14

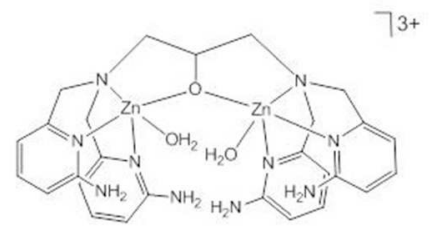

$\left[\mathrm{Zn}_{2} \mathrm{~L} 14\left(\mathrm{H}_{2} \mathrm{O}\right)_{2}\right]^{3+}$<smiles>Cc1cc(CN(Cc2ccccn2)Cc2ccccn2)c(O)c(CN(Cc2ccccn2)Cc2ccccn2)c1</smiles>

HL19

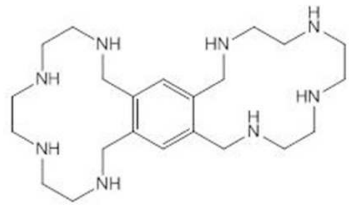

L21<smiles>[Y]c1cccc(CN(Cc2cccc(CN(Cc3cccc([Y])n3)Cc3cccc([Y])n3)c2)Cc2cccc([Y])n2)n1</smiles>

$15 \mathrm{NH}_{2}$ L16 $\mathrm{NH}(\mathrm{C}=\mathrm{O}) \mathrm{CH}_{3}$ L17 $\mathrm{CH}_{3}$

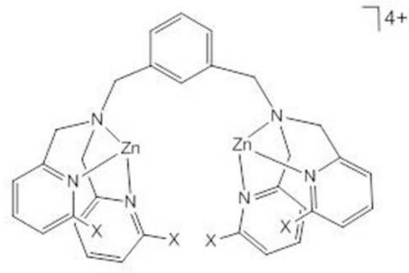

$\left[\mathrm{Zn}_{2} \mathrm{L15}\right]^{4+}$

$\left[\mathrm{Zn}_{2} \mathrm{~L}_{16}\right]^{4+}$<smiles></smiles><smiles>O=[N+]([O-])c1ccc(O)c(/C=N/CCNCC/N=C/c2cc([N+](=O)[O-])ccc2O)c1</smiles><smiles>Cc1cc(CN2CC=C(c3ccccn3)N2)c(O)c(Cn2ccc(-c3ccccn3)n2)c1</smiles>

HL25

FIGURE 11 | Chemical structures of ligands HL13-HL25 and the dinuclear $\mathrm{Zn}(\mathrm{II})$ complexes $\left[\mathrm{Zn}_{2} \mathbf{L} \mathbf{1 3}\right]^{3+},\left[\mathrm{Zn_{2 }} \mathbf{L 1 4}\left(\mathrm{H}_{2} \mathrm{O}\right)_{2}\right]^{3+},\left[\mathrm{Zn} \mathbf{n}_{2} \mathbf{L 1 5}\right]^{4+},\left[\mathrm{Zn} \mathrm{n}_{2} \mathbf{L 1 6}\right]^{4+}$ and $\left[\mathrm{Zn}_{2} \mathbf{L} \mathbf{L 1 7}\right]^{4+}$.

with the experimental data found the substrate to bind via the two phosphoryl oxygens in a bridging mode and via the nucleophilic $2^{\prime}$-OH group. The pre-equilibrium step involving the activation of the $2^{\prime}-\mathrm{OH}$ group through specific-base catalysis by $\mathrm{Zn}-\mathrm{OH}$ is followed by the concerted nucleophilic attack and cleavage of the leaving group bond (Gao et al., 2011). Similar to the mechanism (i) in the DFT study of $\left[\mathrm{Zn}_{2} \mathbf{L 8}\right]^{4+},\left[\mathrm{Zn}_{2} \mathbf{L 1 3}\right]^{3+}$ alters the loose transition state of the uncatalyzed reaction to a more associative or tight one. The second theoretical study published earlier found the same substrate binding mode but proposed a two-step pathway with general base catalysis (Fan and Gao, 2010). It was pointed out that the large rate accelerations of the cleavage of RNA models provided by $\left[\mathrm{Zn}_{2} \mathbf{L} 13\right]^{3+}$ were due to the dominant role of electrostatics in stabilizing the dianionic transition state (Iranzo et al., 2003b; Yang et al., 2005, 2007). The densely charged core of two close packed $\mathrm{Zn}^{2+}$ ions binds the transition state 
with high affinity, leading to a transition state stabilization that is ca. $50 \%$ of that estimated for the corresponding enzymatic reaction. Kinetic analysis revealed $2.1 \mathrm{kcal} \mathrm{mol}^{-1}$ of greater stabilization of the transition state for the cleavage of uridylyl $\left(3^{\prime}\right.$ $\rightarrow \quad 5^{\prime}$ )uridine (UpU) compared to the transition state for the cleavage of uridine- $3^{\prime}$-4-nitrophenyl phosphate (UpPNP) which demonstrates that the transition state stabilization of the developing negative charge on the leaving group oxygen of $U p U$ is stronger than the stabilizing interaction between the catalyst and the C-2' oxyanion nucleophile at the rate-determining transition state of UpPNP cleavage (O’Donoghue et al., 2006).

Mikkola, Williams and coworkers studied the hydrolysis of HPNP, UpU, and uridine-3'-alkyl phosphates by $\left[\mathrm{Zn}_{2} \mathbf{L 1 4}\left(\mathrm{H}_{2} \mathrm{O}\right)_{2}\right]^{3+}$ and observed that the complex not

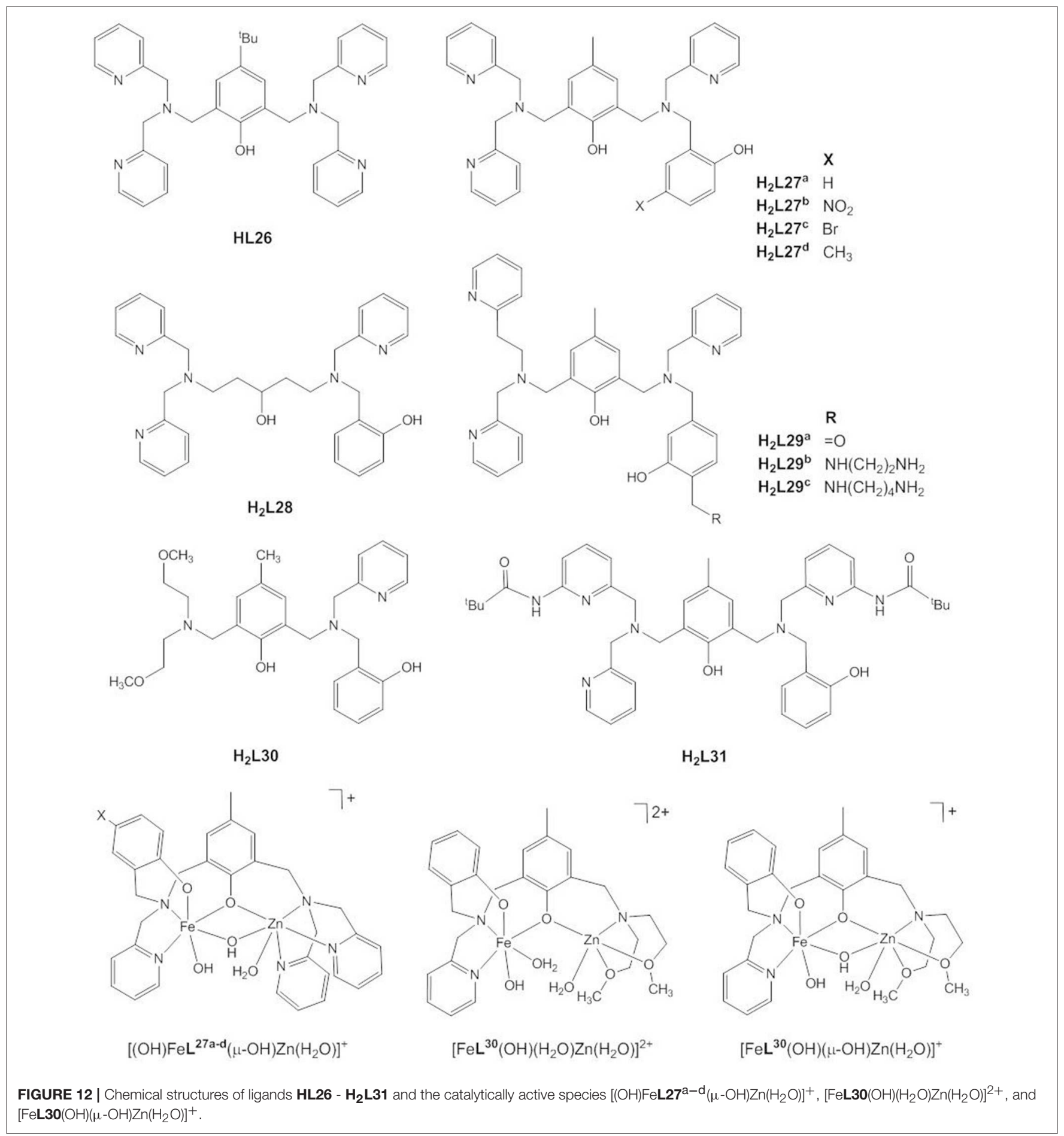


only provides an enormous $10^{6}$-fold rate acceleration of the cleavage reaction in aqueous solution, but also catalyzes the isomerization to the corresponding uridine- $2^{\prime}$-alkyl phosphates (Feng et al., 2006; Linjalahti et al., 2008; Korhonen et al., 2012). This means that the dizinc(II) entity stabilizes the phosphorane intermediate sufficiently to allow pseudorotation, and is clear evidence for a stepwise mechanism. It was proposed that the expulsion of the leaving group is the rate-determining step and is general-acid catalyzed. Cocrystallization of the zinc(II) complex with 4-nitrophenyl phosphate confirmed that the phosphoryl oxygen atoms of the bridging phosphate ester are in hydrogen bonding distance of the four amino substituents. By serving as second-sphere $\mathrm{H}$-bond donors, the amino groups contribute to the stabilization of the dianionic phosphorane and provide a further $10^{3}$-fold rate enhancement of the cleavage of HPNP compared to the unsubstituted complex due to tighter binding of the substrate to the catalyst and to the transition state. Again, it becomes clear that charge neutralization by an electrophilic catalyst plays a dominant role. The dinuclear complex stabilizes the phosphorane to the same extent as complete neutralization of one negative charge and to an extent that enables $3^{\prime} \rightarrow 2^{\prime}$ isomerization. The isomerization is catalyzed less efficiently than the cleavage reaction. While binding to the zinc(II) complex stabilizes the phosphorane, it restrains its conformational change required for isomerization to occur.

Interestingly, Mohamed and Brown found that the dizinc(II) complexes of L15, L16, and L17-having amino, acetamido and methyl substituents, respectively-gave similar increases in $\mathrm{k}_{\text {cat }}$ for the cleavage of HPNP in methanol (Mohamed and Brown, 2010). The kinetic data were interpreted to suggest that hydrogen bonding effects are important for catalysis, but less so for substrate binding. The key conclusion, however, was that the creation of a hydrophobic pocket by the methyl substituents is just as effective as hydrogen bonding. By contrast, methylation of the coordinating nitrogens in $\mathbf{L 8}$ reduces the catalytic efficiency and the synergism between the two $\mathrm{Zn}^{2+}$
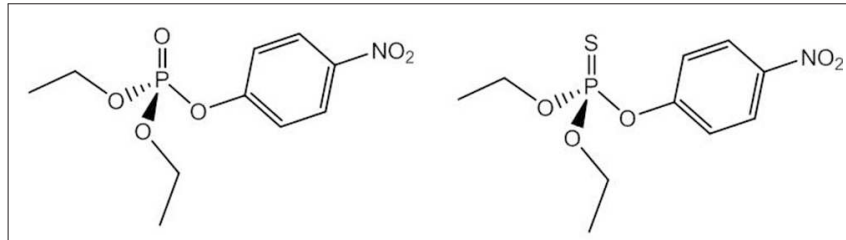

paraoxon

parathion

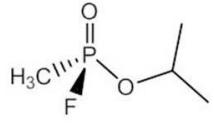

sarin

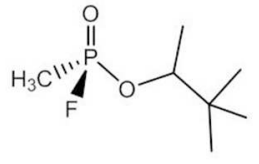

soman
FIGURE 13 | Synthetic phosphotriesters and organophosphates. ions, most likely due to steric effects that impair substrate binding (Song et al., 2012).

Besides introducing substituents, the linker between the two triaza macrocycles in L8 was varied (Liu et al., 2009; Guo et al., 2011). When more rigid aromatic linkers were employed, the synergistic effect of the two metals varied between 5- and 700-fold (Guo et al., 2011). Replacing the propylene linker in $\mathbf{L 8}$ with a butylene linker led to an increase in the activation energy $\Delta \mathrm{G}_{\mathrm{cat}}$ of around 1-1.6 $\mathrm{kcal} \mathrm{mol}^{-1}$, which was attributed to a less tightly bound substrate-catalyst complex at the transition state (Liu et al., 2009). The presence of the 2propoxy linker in $\left[\mathrm{Zn}_{2} \mathbf{L} \mathbf{1 3}\right]^{3+}$ leads to a 37,000 -fold decrease in the catalytic activity toward HPNP in methanol compared to $\left[\mathrm{Zn}_{2} \mathbf{L 8}\left(\mathrm{OCH}_{3}\right)\right]^{3+}$ (Mohamed et al., 2009). Possible reasons for this include the reduction in Lewis acidity of the $\mathrm{Zn}^{2+}$ ions, the higher coordination number of the $\mathrm{Zn}^{2+}$ ions, decreased stabilization of the negative charge development in the transition state and the loss of conformational flexibility (Mohamed et al., 2009; Maxwell et al., 2013). DFT calculations showed that the $\mathrm{Zn}(\mathrm{II}) \cdots \mathrm{Zn}(\mathrm{II})$ distance in $\left[\mathrm{Zn}_{2} \mathbf{L 8}\left(\mathrm{OCH}_{3}\right)\right]^{3+}$ expands from ca. $3.6 \AA$ to over $5 \AA$ in the intermediates and transition states (Maxwell et al., 2013). Likewise, the dinuclear Zn(II) complex of L18 is more active in methanol than the analogous complex of HL19 (Mohamed et al., 2009). Energetics calculations showed a greater stabilization of $3.7 \mathrm{kcal} \mathrm{mol}^{-1}$ of the transition state by the former compared to the latter. Interestingly, the situation seems to be different in aqueous solution. In water, the bridging linker is believed to be crucial to achieve cooperativity between the metal ions (Iranzo et al., 2003a; Morrow, 2008). There is no doubt about the importance of medium effects. While the zinc(II) complex of HL13 is an efficient catalyst in aqueous solution, in ethanol it accelerates the transesterification of HPNP by an impressive 12 orders of magnitude relative to the background reaction at the same ${ }_{s}^{s} \mathrm{pH}$ (Bunn et al., 2007). It has been proposed that the reduced polarity of the solvent results in desolvation of the ionic components and a better solvation and stabilization of the charge-dispersed transition state (Bunn et al., 2007; Korhonen et al., 2012). The effect of a lower dielectric constant on the binding of ions of opposite charge will increase the catalyst-substrate binding constant. Energetics calculations gave a $\Delta G_{\text {stab }}^{\neq}$of $-21 \mathrm{kcal} \mathrm{mol}^{-1}$ for the $\left[\mathrm{Zn}_{2} \mathbf{L} \mathbf{8}\right]^{4+}$. mediated cleavage of HPNP in methanol which is close to the $\Delta G_{\text {stab }}^{\neq}$expected for highly efficient phosphodiesterase enzymes (Bunn et al., 2007).

For $\left[\mathrm{Zn}_{2} \mathbf{L} \mathbf{1 9}(\mu-\mathrm{OH})\right]^{2+}$, a medium effect on the reaction pathway was also described (Selmeczi et al., 2007). DFT calculations indicated that the hydroxypropyl arm of the bridging HPNP is oriented at the hydrogen bonding distance to the $\mu-\mathrm{OH}$ group. This H-bond facilitates the deprotonation of the attacking nucleophile by the hydroxido bridge. In aqueous solution, a further proton transfer to an external hydroxide takes place, while in a non-aqueous medium (DMSO), the protonated $\mu$ $\mathrm{OH}_{2}$ shifts to a terminal position. In both cases DFT calculations agreed with the concurrent deprotonation of $2^{\prime}-\mathrm{OH}$ and P$\mathrm{O}$ bond formation, leading to a pentacoordinate phosphorane which, however, appears to be not as viable in the non-aqueous 
medium. In DMSO, the $\mu_{2}-\kappa^{1} O: \kappa^{1} O^{\prime}$-bridging coordination mode of the cyclophosphate product is in equilibrium with the cyclophosphate forming a monoatomic bridge. This "phosphate shift" was not observed in aqueous solution.

Bim et al. studied dinuclear $\mathrm{Zn}(\mathrm{II})$ complexes with the conformationally constrained bis-polyazamacrocycles L20 - L22 (Bím et al., 2016). Only $\left[\mathrm{Zn}_{2} \mathbf{L} 20\right]^{2+}$ showed catalytic activity in aqueous buffer. Kinetic data and DFT calculations were consistent with two mechanistic scenarios with similar energy barriers and with the substrate coordinating via the two phosphoryl oxygens to both $\mathrm{Zn}$ and via the deprotonated 2hydroxy group to one $\mathrm{Zn}(\mathrm{Zn} 1)$. In mechanism (1) nucleophilic attack and dissociation of the leaving group take place in two steps. In (2) an additional water molecule binds to $\mathrm{Zn} 2$ and the mechanism becomes a one-step process. By contrast, DFT calculations for the unsymmetric complex $\left[\mathrm{Zn}_{2} \mathbf{L} \mathbf{4}(\mu-\mathrm{OH})(\mathrm{OH})\right]$ clearly favor a concerted associative mechanism for HPNP transesterification (Daver et al., 2016). While the deprotonation of the 2-OH nucleophile in a pre-equilibrium step was proposed on the basis of experimental data (Jarenmark et al., 2010), the DFT calculations indicated a significantly lower energy barrier for a general-base mechanism in which the deprotonation of the bridging HPNP by $\mathrm{Zn}-\mathrm{OH}$ and nucleophilic attack occur concomitantly.

Three-metal cooperativity was recently reported for the trinuclear complex $\left[\mathrm{Zn}_{3}(\mathbf{L 2 3})_{2}\left(\mathrm{H}_{2} \mathrm{O}\right)_{4}\right] \cdot \mathrm{H}_{2} \mathrm{O} \cdot 2 \mathrm{DMF}$ (Joshi et al., 2018). It was suggested that the cooperative action of the three metals comprising double Lewis acid activation of the bridging HPNP and base catalysis by the third $\mathrm{Zn}^{2+}$ ion is assisted by the cup-shaped cavity of the complex. The trinuclear complex gives a ca. 4-fold higher $\mathrm{k}_{\text {cat }}$ value than the analogous dinuclear complex $\left[\mathrm{Zn}_{2}(\mathbf{L} 24)_{2}\left(\mathrm{H}_{2} \mathrm{O}\right)_{2}\right]\left(\mathrm{ClO}_{4}\right)_{2}$, for which monodentate substrate coordination to $\mathrm{Zn} 1$ and base catalysis by $\mathrm{Zn} 2-\mathrm{OH}$ were proposed.
As discussed in a previous section, there are conflicting data in the literature on the correlation between the catalytic activity of phosphoesterase models and the Lewis acidity of the metal ion(s). Arora et al. compared the rate acceleration of HPNP transesterification provided by $\left[\mathrm{Zn}_{2} \mathbf{L} \mathbf{2 5}\left(\mathrm{H}_{2} \mathrm{O}\right)_{\mathrm{x}}(\mathrm{OH})_{\mathrm{y}}\right]^{\mathrm{n}+}$ and the analogous $\mathrm{Co}(\mathrm{II})$ and $\mathrm{Mn}$ (II) complexes and found a linear correlation of the rate constant $\mathrm{k}_{2}$ with the $\mathrm{Z}_{\mathrm{eff}} / \mathrm{r}$ value of the metal ion (Arora et al., 2012). Thus, Lewis acid activation of the phosphorus is more important than activation of the nucleophile in this case. It may be relevant that the nucleophile is an internal one that is per se more efficient than the external one for general phosphate ester substrates.

As is evident from the above, in the majority of studies the model substrate HPNP was used. Some caution must be exercised when applying conclusions drawn from these analyses to RNA. It has been pointed out in the literature that the 2-OH group in HPNP is more flexible than the ribose $2^{\prime}-\mathrm{OH}$ and also has a higher $\mathrm{pK}_{\mathrm{a}}$ value (Korhonen et al., 2012). Hydrophobic and $\pi$-stacking interactions between the linker moiety or heteroaromatic binding site of a dinuclear ligand and the 4-nitrophenyl group have been demonstrated to enhance substrate binding and to increase the catalytic activity (Bazzicalupi et al., 2004). Leivers and Breslow showed that this can incorrectly suggest cooperativity between two metal centers (Leivers and Breslow, 2001). Furthermore, the literature shows that the rate-determining step depends on the nature of the leaving group, when the reaction proceeds through the $A_{N}+D_{N}$ mechanism (vide supra). Mikkola and coworkers published a comprehensive analysis of the dizinc(II) complex-mediated cleavage of uridine- $3^{\prime}$-aryl and uridine- $3^{\prime}$ alkyl phosphates. The observed cooperativity of the two metals in dinuclear catalysts changes with the acidity of the leaving group of the substrate. In the case of alkyl groups, the cooperativity decreases with decreasing acidity, whereas in the case of aryl

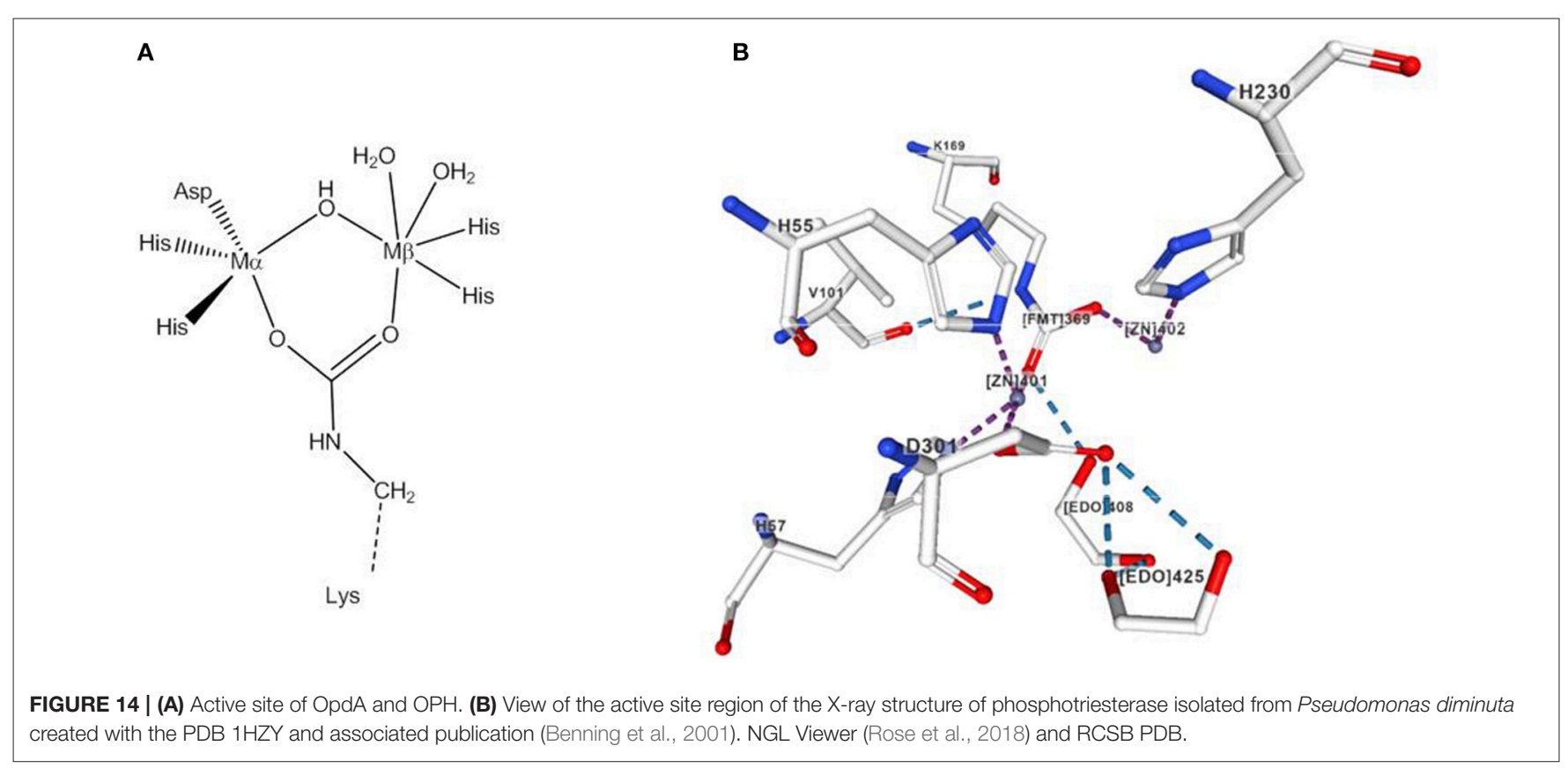


phosphates the cooperativity increases with decreasing acidityi.e., as nucleophilic attack becomes more rate-determining. They concluded that there is no universal mechanism for the transesterification of RNA and its analogs that covers all substrate-catalyst combinations (Korhonen et al., 2013).

\section{Phosphodiester Hydrolysis Catalyzed by Heterodinuclear Fe(III)Zn(II) Complexes}

Following earlier work by Borovik and Que and by Wieghardt and coworkers who synthesized heterodinuclear, carboxylate-/ hydroxide-bridged Fe(III)/M(II) complexes to model iron-oxido proteins (Borovik et al., 1988; Hotzelmann et al., 1992), a number of biomimetic studies were targeted specifically at the mechanism of the heterodinuclear Fe(III)Zn(II) site of plant PAPs. Pathak et al. reported the Fe(III) $\mathrm{Zn}$ (II) complex of the symmetric ligand HL26 (Pathak et al., 2018), but usually unsymmetric ligands with the two binding sites differing in the number and/or nature of the donor atoms are employed to stabilize the heterodimetallic site (Figure 12). $\mathbf{H}_{2} \mathbf{L} 27^{\mathrm{a}}$ was specifically designed to provide a hard $\mathrm{N}_{2} \mathrm{O}_{4}$ site for the trivalent $\mathrm{Fe}(\mathrm{III})$, and a softer $\mathrm{N}_{3} \mathrm{O}_{3}$ site for the divalent $\mathrm{Zn}$ (II) in the presence of additional bridging carboxylate or hydroxido ligands and to model the terminal tyrosinate ligand in PAP (Lanznaster et al., 2002; Neves et al., 2007). Single crystal structures of both the acetate- and hydroxido-bridged complexes, $\quad\left[\mathrm{Fe}(\mathrm{III}) \mathrm{Zn}(\mathrm{II}) \mathrm{L}^{2} 7^{\mathrm{a}}\left(\mu-\mathrm{CH}_{3} \mathrm{COO}_{2}\right)_{2}\right] \mathrm{ClO}_{4}$ and $\left[\left(\mathrm{H}_{2} \mathrm{O}\right) \mathrm{Fe}(\mathrm{III}) \mathrm{Zn}(\mathrm{II}) \mathbf{L}^{2} 7^{\mathrm{a}}(\mu-\mathrm{OH})\right]\left(\mathrm{ClO}_{4}\right)_{2}$, could be obtained showing that the $\mathrm{M}(\mathrm{III}) \cdots \mathrm{M}$ (II) distance decreases from 3.490(9) to $3.040(1) \AA$ when the carboxylate ligands are replaced with a $\mu-\mathrm{OH}$ ligand. The $\mathrm{Fe}(\mathrm{III}) \cdots \mathrm{Zn}(\mathrm{II})$ distance in the latter is slightly shorter but comparable to that of $3.20 \AA$ in red kidney bean PAP (Klabunde et al., 1996).

While in the majority of the $\mathrm{Fe}(\mathrm{III}) \mathrm{Zn}(\mathrm{II})$ complexes of $\mathbf{H L 2 6}-\mathbf{H}_{2} \mathbf{L} 3 \mathbf{1}$ the metals are bridged by two acetates in the solid state, in solution dissociation of the acetate ligands leads to $\left[\left(\mathrm{H}_{2} \mathrm{O}\right) \mathrm{Fe} \mathbf{L}\left(\mu-\mathrm{OH}_{2}\right) \mathrm{Zn}\left(\mathrm{H}_{2} \mathrm{O}\right)\right]^{\mathrm{n}+},\left[\left(\mathrm{H}_{2} \mathrm{O}\right) \mathrm{Fe} \mathbf{L}(\mu-\right.$ $\left.\mathrm{OH}) \mathrm{Zn}\left(\mathrm{H}_{2} \mathrm{O}\right)\right]^{(\mathrm{n}-1)+},\left[(\mathrm{OH}) \mathrm{FeL}(\mu-\mathrm{OH}) \mathrm{Zn}\left(\mathrm{H}_{2} \mathrm{O}\right)\right]^{(\mathrm{n}-2)+}$, and $[(\mathrm{OH}) \mathrm{FeL}(\mu-\mathrm{OH}) \mathrm{Zn}(\mathrm{OH})]^{(\mathrm{n}-3)+}$ species, depending on the $\mathrm{pH}$ value (Lanznaster et al., 2002; Neves et al., 2007; Peralta et al., 2010; Piovezan et al., 2010; Jarenmark et al., 2011; Roberts et al., 2015; Pathak et al., 2017). Rate-pH profiles and potentiometric titration data indicate that $\left[(\mathrm{OH}) \mathrm{Fe} \mathbf{L}(\mu-\mathrm{OH}) \mathrm{Zn}\left(\mathrm{H}_{2} \mathrm{O}\right)\right]^{\mathrm{n}+}$, which is present in weakly acidic solution is the catalytically active species. In all cases the kinetic data are consistent with the mechanism of PAP proposed by Klabunde et al. (Figure 2B, Klabunde et al., 1996). The phosphodiester replaces the Znbound water in a monodentate binding mode while $\mathrm{Fe}(\mathrm{III})-\mathrm{OH}$ acts as the nucleophile.

The effect of substituents in para position to the terminallybound phenolate oxygen in $\mathbf{H}_{\mathbf{2}} \mathbf{L} \mathbf{2} \mathbf{7}^{\mathrm{a}-\mathrm{d}}$ confirms the role of $\mathrm{Fe}(\mathrm{III})$ as the provider of the nucleophile. Electron-withdrawing groups $\left(\mathrm{NO}_{2}, \mathrm{Br}\right)$ lead to a decrease in the hydrolysis rate, while electron-donating groups $\left(\mathrm{CH}_{3}\right)$ enhance the phosphodiesterase activity (Peralta et al., 2010). The higher the electron-donating property of the ligand, the lower the Lewis acidity of the metal ion is and the weaker the $\mathrm{M}-\mathrm{OH}$ interaction is. When there is less pull of the electron density by the metal, the metal-bound hydroxide presents a stronger nucleophile. The observation that the analogous $\mathrm{Ga}(\mathrm{III}) \mathrm{Zn}$ (II) complex of $\mathbf{H}_{2} \mathbf{L} \mathbf{2} 7^{\mathrm{a}}$ hydrolyses BDNPP more efficiently than does the Fe(III)Zn(II) complex is also in line with nucleophilic attack by $\mathrm{M}(\mathrm{III})-\mathrm{OH}$ (Smith et al., 2007). The authors of the study attributed the higher catalytic activity of the Ga(III) $\mathrm{Zn}$ (II) complex to the importance of the higher lability of $\mathrm{Ga}$ (III) compared to $\mathrm{Fe}$ (III) when product release is the rate-determining step. However, the difference in the $\mathrm{pK}_{\mathrm{a}}$ value of $\mathrm{Ga}(\mathrm{III})-\mathrm{OH}_{2}\left(\mathrm{pK}_{\mathrm{a}}=5.59\right)$ and $\mathrm{Fe}(\mathrm{III})\left(\mathrm{pK}_{\mathrm{a}}=4.86\right)$ may also suggest that $\mathrm{Ga}(\mathrm{III})$ provides a stronger nucleophile.

Ferreira et al. carried out DFT calculations on the reaction mechanism of the hydrolysis of dimethyl phosphate by the closely related complex $[(\mathrm{OH}) \mathrm{Fe} \mathbf{L} 28(\mu-\mathrm{OH}) \mathrm{Zn}]^{+}$(Ferreira et al., 2008). The optimized structure of the substrate-catalyst complex showed that substrate binding is stabilized by a H-bond between $\mathrm{Fe}-\mathrm{OH}$ and a phosphoryl oxygen with a Gibbs free energy variation of $-55.1 \mathrm{kcal} \mathrm{mol}^{-1}$. The hydrolysis reaction proceeds by a two-step associative mechanism. The first, rate-determining step involves the nucleophilic attack of Fe-OH at the $\mathrm{Zn}$-bound phosphodiester resulting in the pentacoordinate phosphorane intermediate. The movement of the $\mathrm{OH}$ group toward the phosphorus and P-O bond formation is accompanied by a fast proton transfer from $\mathrm{OH}$ to the phosphoryl oxygen. In the second step, the simultaneous proton transfer from $\mathrm{P}-\mathrm{OH}$ to the leaving group oxygen and breaking of the leaving group bond lead to the release of $\mathrm{CH}_{3} \mathrm{OH}$.

$\mathbf{H}_{2} \mathbf{L}^{29^{a}}, \mathbf{H}_{2} \mathbf{L}^{2} 9^{b}$, and $\mathbf{H}_{2} \mathbf{L} \mathbf{2 9}^{c}$ were synthesized to model secondary interactions between the phosphate ester substrate and positively charged amino acid residues in the active site of PAP (Silva et al., 2017). The presence of the side chains in $\mathrm{H}_{2} \mathbf{L} 2 \mathbf{9}^{\mathrm{b}}$ and $\mathrm{H}_{2} \mathrm{~L}^{2} \mathbf{9}^{\mathrm{c}}$ led to a decrease in the $\mathrm{pK}_{\mathrm{a}}$ value of $\mathrm{Fe}(\mathrm{III})-\mathrm{OH}_{2}$ by 0.6 and $0.8 \mathrm{pH}$ units compared to the parent complex and to a shift of the redox potential of $\mathrm{Fe}$ (III) to less negative values. This was rationalized by hydrogen bonding between the ammonium group of the side chain and the bridging hydroxide as observed in the optimized solid-state structures of $\left[\mathrm{Fe} \mathbf{L 2 9}^{\mathrm{b}}(\mathrm{OH})(\mu-\mathrm{OH}) \mathrm{Zn}\left(\mathrm{H}_{2} \mathrm{O}\right)\right]\left(\mathrm{ClO}_{4}\right)_{2}$ and $\left[\mathrm{FeL29}^{\mathrm{c}}(\mathrm{OH})(\mu-\mathrm{OH}) \mathrm{Zn}\left(\mathrm{H}_{2} \mathrm{O}\right)\right]\left(\mathrm{ClO}_{4}\right)_{2}$. The higher $\mathrm{k}_{\mathrm{cat}}$ and lower $\mathrm{K}_{\mathrm{m}}$ values of $\left[\mathrm{FeL29} \mathbf{9}^{\mathrm{b}}(\mathrm{OH})(\mu-\mathrm{OH}) \mathrm{Zn}\left(\mathrm{H}_{2} \mathrm{O}\right)\right]\left(\mathrm{ClO}_{4}\right)_{2}$ and $\left[\mathrm{FeL29} \mathbf{L}^{\mathrm{c}}(\mathrm{OH})(\mu-\mathrm{OH}) \mathrm{Zn}\left(\mathrm{H}_{2} \mathrm{O}\right)\right]\left(\mathrm{ClO}_{4}\right)_{2}$ compared to $\left[\mathrm{FeL29}(\mathrm{OH})(\mu-\mathrm{OH}) \mathrm{Zn}\left(\mathrm{H}_{2} \mathrm{O}\right)\right]\left(\mathrm{ClO}_{4}\right)_{2}$ reflect the enhanced binding affinity of the substrate for the side-chain bearing complexes. The changes in $\mathrm{K}_{\mathrm{m}}$ were found to correlate with the proximity of the side chain to the phosphate group in the optimized structures of the catalyst-substrate complexes. Camargo et al. attached one and two pyrene moieties via a diamine spacer to the ortho position of the phenol ring in $\mathbf{H}_{2} \mathbf{L 2 7}^{\text {a }}$ (Camargo et al., 2018). They suggested that the 6-fold increase in $\mathrm{K}_{\mathrm{ass}}$ for BDNPP was due to H-bond formation and hydrophobic interactions between pyrene and 4-nitrophenol. The determination of the activation parameters for BDNPP hydrolysis revealed a decrease of $\Delta H^{\neq}$by ca $10 \mathrm{~kJ} \mathrm{~mol}^{-1}$ with respect to the corresponding complex having a carbonyl group as a substituent, and this was attributed to hydrogen bonding and the stabilization of the negatively charged transition state. However, this favorable enthalpic contribution was offset by a 
less favorable $\Delta S^{\neq}$, probably due to a higher degree of structural organization in the transition state.

The unsymmetric ligand $\mathbf{H}_{2} \mathbf{L} 30$ provides an $\mathrm{N}_{2} \mathrm{O}_{2}$ and an $\mathrm{NO}_{3}$ site. The speciation plot and rate-pH profile suggest that its $\mathrm{Fe}(\mathrm{III}) \mathrm{Zn}(\mathrm{II})$ complex mimics the mechanistic flexibility of PAP (Roberts et al., 2015). At a low $\mathrm{pH}$, $\left[\mathrm{Fe} \mathbf{L 3 0}(\mathrm{OH})\left(\mathrm{H}_{2} \mathrm{O}\right) \mathrm{Zn}\left(\mathrm{H}_{2} \mathrm{O}\right)\right]^{2+}$ is the active species and the terminally bound $\mathrm{OH}$ acts as the nucleophile. At higher $\mathrm{pH}$, the bridging $\mathrm{OH}$ of $\left[\mathrm{FeL30}(\mathrm{OH})(\mu-\mathrm{OH}) \mathrm{Zn}\left(\mathrm{H}_{2} \mathrm{O}\right)\right]^{+}$ becomes the nucleophile. $\left[\mathrm{FeL} \mathbf{3 0}(\mathrm{OH})(\mu-\mathrm{OH}) \mathrm{Zn}\left(\mathrm{H}_{2} \mathrm{O}\right)\right]^{+}$is the better catalyst. Jarenmark et al. synthesized $[\mathrm{FeZnL4}(\mu-$ $\left.\left.\mathrm{CH}_{3} \mathrm{COO}\right)_{2}\left(\mathrm{CH}_{3} \mathrm{OH}\right)\right] \mathrm{PF}_{6}$ to model the distinct donor atoms as well as the different coordination numbers of Fe(III) and Zn(II) in PAP (Jarenmark et al., 2011). The complex hydrolyzes BDNPP and also shows some activity toward HPNP. At high $\mathrm{pH}$ the complex converts to an inactive $\mu$-oxido-bridged dimer of heterodinuclear dimers.

HL9, HL10, and $\mathbf{H}_{2}$ L31 contain sterically demanding pivaloyl-amide substituents. A detailed kinetic analysis of the hydrolysis of BDNPP by the respective heterodinuclear $\mathrm{Ga}(\mathrm{III}) \mathrm{Zn}$ (II), homodinuclear $\mathrm{Zn}(\mathrm{II})_{2}$, mononuclear $\mathrm{Zn}(\mathrm{II})$, and $\mathrm{Ga}(\mathrm{III})$ complexes gave insight into the influence of the secondary coordination sphere, the effect of the properties of the binding site and the role of the heterodinuclear site (Bosch et al., 2016). Hydrogen bonding capacity shifts the $\mathrm{pH}$ optimum to higher $\mathrm{pH}$ values. The presence of $\mathrm{H}$-bond donating substituents also leads to higher hydrolysis rates and higher catalytic efficiencies, especially when the two $\mathrm{H}$-bond donors are located proximal to the $\mathrm{Zn}$ (II) site. The Ga(III)Zn(II) complex of HL9 hydrolyses BDNPP faster and with larger turnover numbers than the corresponding HL10 complex. However, the introduction of the $\mathrm{H}$-bond donating substituents decreases the substrate affinity, which may be a steric effect. A comparison of HL9 and $\mathbf{H}_{2} \mathbf{L} 31$ showed that the $\mathrm{pH}$ optimum shifts to lower $\mathrm{pH}$ values when the binding site becomes more electron-rich. The catalytic activity of the heterodinuclear complex of HL10 is greater than the sum of the activities of the mononuclear $\mathrm{Zn}$ (II) and $\mathrm{Ga}$ (III) complexes confirming the cooperativity of the metals in the dimetallic site. The Ga(III)Zn(II) complex of HL9 hydrolyzes BDNPP about 20 times faster at $\mathrm{pH} 7$ than the dizinc(II) complex. Interestingly, $\mathrm{K}_{\mathrm{m}}$ is three times higher for the $\mathrm{Ga}(\mathrm{III}) \mathrm{Zn}$ (II) complex. A weaker substrate affinity of the heterodinuclear complex compared to the corresponding homodinuclear $\mathrm{Zn}(\mathrm{II})_{2}$ complex was also seen for $\left[\mathrm{Fe}(\mathrm{III}) \mathrm{Zn}(\mathrm{II}) \mathbf{L} 26\left(\mu-\mathrm{CH}_{3} \mathrm{COO}\right)_{2}\right]^{2+}$ (Pathak et al., 2018). It appears that the electronic effect of the heterodimetallic site on substrate and/or nucleophile activation is more important than the formation of the catalyst/substrate complex.

\section{Hydrolysis of Phosphotriesters and Organophosphates}

Due to their neutral charge phosphotriesters are more easily hydrolyzed at $\mathrm{pH} 7$ than phosphodi- and -monoesters. The mechanism of the uncatalyzed reaction is believed to be associative with both a two-step addition-elimination and a concerted pathway being possible. Phosphotriesters do not occur naturally. Synthetic organophosphate triesters have been widely used as pesticides and insecticides (e.g., paraoxon, parathion, Figure 13). In mammals, they cause nerve and organ failure due to their ability to inhibit acetylcholinesterase and some highly toxic organophosphorus compounds such as sarin and soman are employed as chemical warfare agents (Raushel, 2002). Bacterial phosphotriesterases can degrade phosphotriesters and their analogs into less toxic diesters and have probably evolved in response to the intense application of synthetic organophosphates in agriculture (Donarski et al., 1989; Dumas et al., 1990).

Two of the best-studied phosphotriesterases are the Zn-containing organophosphate degrading enzymes from Agrobacterium radiobacter (OpdA) and organophosphate hydrolase from Pseudomonas diminuta (OPH). Glycerophosphodiesterase from Enterobacter aerogenes (GpdQ) is also known to hydrolyze organophosphate triesters. OpdA and $\mathrm{OPH}$ share a high sequence and structure homology

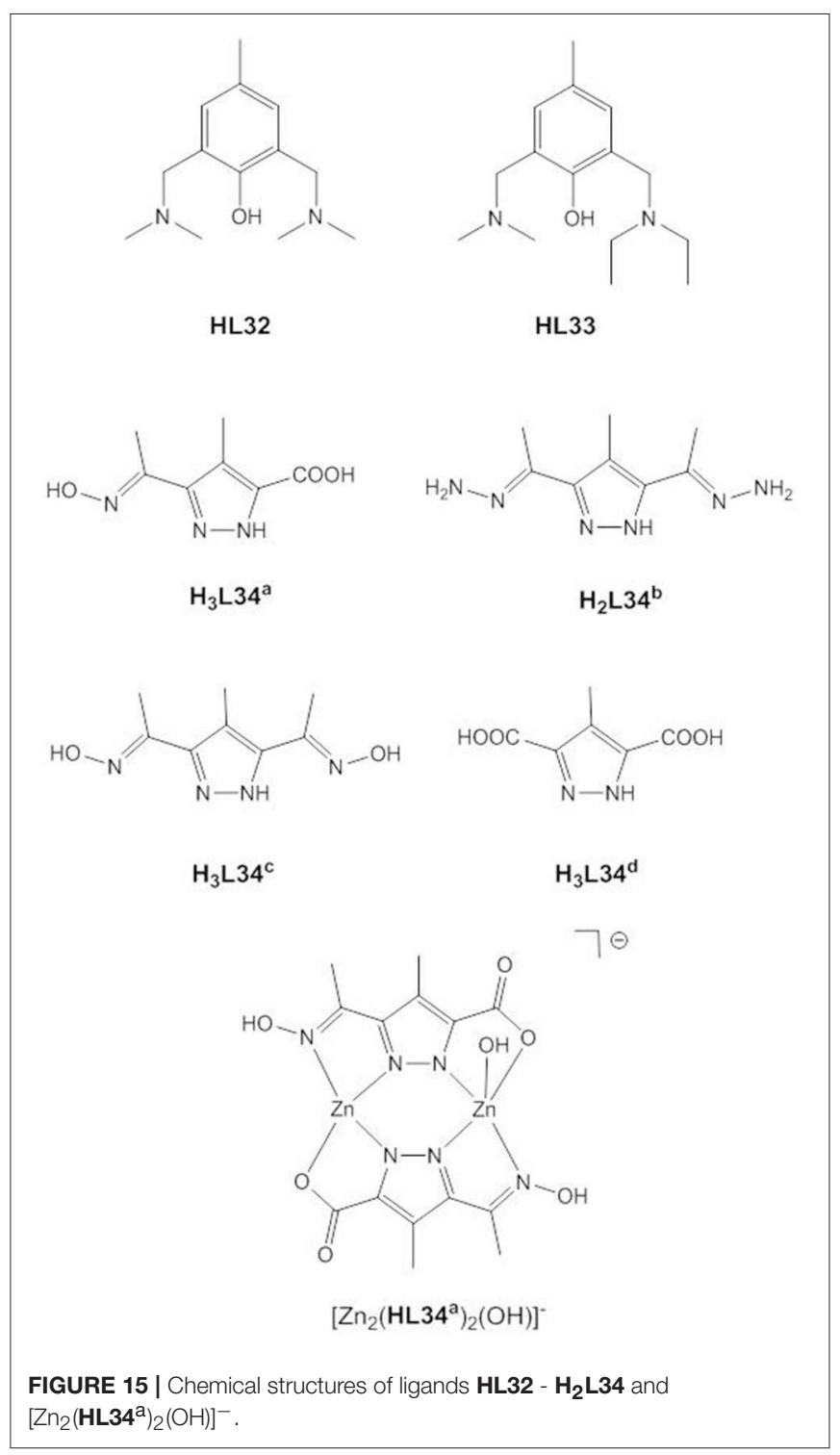


(Yang et al., 2003). In their active site two $\mathrm{Zn}^{2+}$ ions, referred to as $\alpha$ - and $\beta$-site are bridged by a carboxylated lysine side chain and a hydroxide/water (Benning et al., 2001; Figure 14). Small-molecule models of OpdA have been previously reviewed (Daumann et al., 2014).

The mechanism of enzymatic phosphotriester hydrolysis was investigated in theoretical studies that indicated an associative pathway involving binding of the phosphoryl oxygen to the $\beta$ site and nucleophilic attack by the bridging hydroxide (Ely et al., $2010,2011)$. On substrate coordination, the $\mu-\mathrm{OH}$ bond to the $\beta$-site weakens and the bridging hydroxide shifts to a pseudoterminal position. However, like PAPs, phosphotriesterases appear to exhibit mechanistic flexibility. Experimental and theoretical studies showed that in the case of the $\mathrm{Co}$ (II) form of OpdA under alkaline conditions, the $\mu-\mathrm{OH}$ group shifts to the $\beta$-site following substrate binding and a hydroxide or water from the environment coordinates terminally to the $\alpha$-site to act as the reaction-initiating nucleophile (Ely et al., 2010, 2011). There is also evidence that the rate-determining step varies with the nature of the leaving group. For leaving groups with a $\mathrm{pK}_{\mathrm{a}}>7$, $\mathrm{P}-\mathrm{O}$ bond cleavage seems to be rate-determining (Ely et al., 2010). Based on kinetic and crystallographic data and computational modeling of the $\mathrm{Fe}$ (II) Zn(II) form of OpdA Jackson et al. proposed that the bridging hydroxide serves as a base and deprotonates a water molecule terminally coordinated to the $\alpha$-site (Jackson et al., 2008). However, such a mechanism appears unlikely for the dizinc(II) form of OPH (Kim et al., 2008).

To address the need for effective bioremediators to decontaminate organophosphate-containing water and soil, biomimetic zinc(II) sites have been assembled into metal-organic frameworks or onto graphene oxide, and promising catalysts are described in the recent literature (Jacques et al., 2008; Ma et al., 2017; Xia et al., 2017). However, detailed mechanistic studies using model complexes and phosphotriesters are rarely reported and most of our current mechanistic understanding of dizinc(II) phosphotriesterases stems from theoretical studies such as those described above. In contrast to the polymer and metal organic framework-based active catalysts, little success has been achieved so far in the development of low-molecular-weight dizinc(II) phosphotriesterase mimics. Only modest phosphotriesterase activity was observed for the small number of dinuclear zinc(II) complexes investigated (Figure 15). The low activities of $\left[\mathrm{Zn}_{2} \mathbf{L 3 2}\left(\mu-\mathrm{CH}_{3} \mathrm{COO}\right)\left(\mathrm{CH}_{3} \mathrm{COO}\right)_{2}\left(\mathrm{H}_{2} \mathrm{O}\right)\right]$ (Tamilselvi and Mugesh, 2010) and $\left[\mathrm{Zn}_{2} \mathbf{L} 33\left(\mu-\mathrm{CH}_{3} \mathrm{COO}\right)\left(\mathrm{CH}_{3} \mathrm{COO}\right)_{2}\left(\mathrm{H}_{2} \mathrm{O}\right)\right]$ (Umayal and Mugesh, 2011) toward 4-nitrophenyl diphenyl phosphate was attributed to inhibition by the phosphodiester hydrolysis product that binds in a bridging mode to the dizinc(II) site. Two of the few examples of dizinc(II) complexes with phosphotriesterase activity were reported by Guo et al. (Guo et al., 2015). [ $\left.\mathrm{Zn}_{2} \mathbf{L} 5\right]^{+}$and $\left[\mathrm{Zn}_{2} \mathbf{L} 7\right]^{-}$hydrolyze sarin at $303 \mathrm{~K}$ with $\mathrm{k}_{\text {cat }} / \mathrm{K}_{\mathrm{m}}$ values of 0.051 and $0.11 \mathrm{~s}^{-1} \mathrm{M}^{-1}$, respectively. DFT calculations confirmed a stepwise associative mechanism with a pentacoordinate phosphoryl intermediate. One of the Zn1-bound alkoxides serves as a general base and deprotonates an incoming water nucleophile which attacks the phosphorus of the Zn2-coordinated substrate. In the catalyst-substrate complex the incoming water molecule hydrogen bonds to $\mathrm{Zn}-\mathrm{OR}$ and to another alkoxide that bridges $\mathrm{Zn} 1$ and $\mathrm{Zn} 2$. $\mathrm{P}_{-} \mathrm{O}_{\mathrm{w}}$ bond formation and proton transfer from the water molecule to the terminal alkoxide occur simultaneously. The higher catalytic activity of $\left[\mathrm{Zn}_{2} \mathbf{L} 7\right]^{-}$was attributed to the higher basicity of the alkoxide groups in L7 compared to L5.

Penkova et al. investigated the hydrolysis of paraoxon by a series of dinuclear pyrazolate complexes (Penkova et al., 2009). The $\mathrm{Zn}(\mathrm{II}) \cdots \mathrm{Zn}$ (II) distances in $\left.\left[\mathrm{Zn}_{2}\left(\mathbf{H L 3 4}^{\mathrm{a}}\right)_{2} \text { (pyridine }\right)_{2}\right]$, $\left[\mathrm{Zn}_{2}\left(\mathbf{H L 3 4}^{\mathrm{b}}\right)_{2}\left(\mathrm{CH}_{3} \mathrm{COO}\right)_{2}\right], \quad\left[\mathrm{Zn}_{2}\left(\mathbf{H}_{2} \mathbf{L}^{\mathbf{C}^{\mathrm{c}}}\right)_{2}\left(\mathrm{NO}_{3}\right)_{2}\right] \quad$ and $(\mathrm{imH})_{2}\left[\mathrm{Zn}_{2}\left(\mathbf{L 3 4}^{\mathrm{d}}\right)_{2}\left(\mathrm{H}_{2} \mathrm{O}\right)_{4}\right](\mathrm{imH}=$ imidazolium) range from 3.75 to $4.115 \AA$, i.e., are longer than those in phenoxidebridged enzyme models and close to the metal-metal distance in alkaline phosphatase (4.0 ̊̊, Stec et al., 2000). Based on the kinetic data and speciation in solution it was proposed that the phosphotriester binds monodentally to one $\mathrm{Zn}(\mathrm{II})$ of $\left[\mathrm{Zn}_{2}\left(\mathbf{H L 3 4}^{\mathrm{a}}\right)_{2}(\mathrm{OH})\right]^{-}$, while the other $\mathrm{Zn}$ (II) provides a metal-bound hydroxide as the nucleophile. $\left[\mathrm{Zn}_{2}\left(\mathbf{L 3 4}^{\mathrm{d}}\right)_{2}\left(\mathrm{H}_{2} \mathrm{O}\right)_{4}\right]^{2-}$ gave a two-fold lower rate acceleration compared to $\left[\mathrm{Zn}_{2}\left(\mathrm{L34}^{\mathrm{a}}\right)_{2}(\mathrm{OH})\right]^{-}$, which was attributed to the lack of $\mathrm{Zn}-\mathrm{OH}$. The relatively small difference in activity between $\left[\mathrm{Zn}_{2}\left(\mathbf{L 3 4}^{\mathrm{a}}\right)_{2}(\mathrm{OH})\right]^{-}$and $\left[\mathrm{Zn}_{2}\left(\mathbf{L} 34^{\mathrm{d}}\right)_{2}\left(\mathrm{H}_{2} \mathrm{O}\right)_{4}\right]^{2-}$ led the authors to the conclusion that Lewis activation is more important for efficient catalysis than metal hydroxide activation. Although the rate constants for the uncatalyzed cleavage of paraoxon and the RNA model HPNP are comparable, the pyrazolate complexes cleave HPNP with a second order rate constant that is about one order of magnitude larger than that for the hydrolysis of paraoxon. This was rationalized with the bridging coordination of the phosphodiester to the dizinc(II) site allowing for double Lewis acid activation.

\section{CONCLUDING REMARKS}

It is hoped that this review has shown that the metal catalysis of what appears to be a rather simple chemical reaction has been and continues to be a challenging research question. Model studies using dinuclear zinc(II) complexes have given insight into the possible roles of the $\mathrm{Zn}^{2+}$ ions in the dimetallic active sites of phosphatases, the potential effects of metal-substrate interaction on transition state stabilization and the contribution of the different interaction modes to the lowering of the overall energy barrier. In this regard smallmolecule biomimetics have proven to be extremely powerful tools. Less has been learned from small-molecule phosphatase models on the actual mechanistic pathway of the natural enzymes, e.g., distinguishing between a monodentate substrate coordination/terminal $\mathrm{Zn}-\mathrm{OH}$ nucleophile mechanism and a bridging substrate coordination $/ \mu-\mathrm{OH}$ nucleophile mechanism for a specific phosphoesterase and this is not the aim of model studies. There is no universal mechanism for the catalysis of phosphate esters by dinuclear dizinc(II) phosphoesterases. Even when a particular phosphoesterase is considered, there is accumulating evidence that phosphoesterases with a low substrate specificity hydrolyze different substrates by distinct mechanisms. 
Small-molecule enzyme models have inherent limitations. They lack the pre-organization of enzymatic sites and the surrounding protein matrix that supports the correct substrate orientation and provides a hydrophobic environment. While the latter has been modeled by non-aqueous media and model systems are increasingly designed to take secondary interactions into account by introducing substituents with hydrogen bonding functionality, it is still (and probably will always be) impossible to mimic the complexity of natural enzymes. Studies in nonaqueous solvents showed a clear effect of the medium on the catalytic activity, but an effect on the mechanism (e.g., $A_{N} D_{N}$ vs. $\left.A_{N}+D_{N}\right)$ must also be considered. Most experimental studies using small-molecule phosphatase models rely on kinetic data, which highlights the inherent difficulty that the data can support different, kinetically equivalent mechanisms. The use of 4-nitrophenyl esters as DNA and RNA models has been criticized in the literature (Menger and Ladika, 1987) and a few caveats have been pointed out in this review. On the other hand, systematic studies with different phosphate esters have shown changes in the mechanism and the rate-determining step,

\section{REFERENCES}

Anbu, S., Kamalraj, S., Varghese, B., Muthumary, J., and Kandaswamy, M. (2012). A series of oxyimine-based macrocyclic dinuclear zinc(II) complexes enhances phosphate ester hydrolysis, DNA binding, DNA hydrolysis, and lactate dehydrogenase inhibition and induces apoptosis. Inorg. Chem. 51, 5580-5592. doi: 10.1021/ic202451e

Anderson, B., Milburn, R. M., Harrowfield, J. M., Robertson, G. B., and Sargeson, A. M. (1977). Cobalt(III)-promoted hydrolysis of a phosphate ester. J. Am. Chem. Soc. 99, 2652-2661. doi: 10.1021/ja00450a042

Arora, H., Barman, S. K., Lloret, F., and Mukherjee, R. (2012). Isostructural dinuclear phenoxo-/acetato-bridged manganese(II), cobalt(II), and zinc(II) complexes with labile sites: kinetics of transesterification of 2-hydroxypropylp-nitrophenylphosphate. Inorg. Chem. 51, 5539-5553. doi: 10.1021/ic 201971t

Bauer-Siebenlist, B., Meyer, F., Farkas, E., Vidovic, D., and Dechert, S. (2005). Effect of $\mathrm{Zn} \cdot$. $\mathrm{Zn}$ separation on the hydrolytic activity of model dizinc phosphodiesterases. Chem. Eur. J. 11, 4349-4360. doi: 10.1002/chem.200400932

Bazzicalupi, C., Bencini, A., Berni, E., Bianchi, A., Fedi, V., Fusi, V., et al. (1999). Carboxy and diphosphate ester hydrolysis by a dizinc complex with a new alcohol-pendant macrocycle. Inorg. Chem. 38, 4115-4122. doi: $10.1021 /$ ic9902929

Bazzicalupi, C., Bencini, A., Berni, E., Bianchi, A., Fornasari, P., Giorgi, C., et al. (2004). $\mathrm{Zn}(\mathrm{II})$ coordination to polyamine macrocycles containing dipyridine units. New insights into the activity of dinuclear $\mathrm{Zn}$ (II) complexes in phosphate ester hydrolysis. Inorg. Chem. 43, 6255-6265. doi: 10.1021/i c049754v

Bazzicalupi, C., Bencini, A., Bianchi, A., Fusi, V., Giorgi, C., Paoletti, P., et al. (1997). Carboxy and phosphate esters cleavage with mono- and dinuclear zinc(II) macrocyclic complexes in aqueous solution. Crystal structure of $\left[\mathrm{Zn}_{2} \mathrm{Ll}(\mu-\mathrm{PP})_{2}(\mathrm{MeOH})_{2}\right]\left(\mathrm{ClO}_{4}\right)_{2} \quad\left(\mathrm{~L} 1=[30] \mathrm{aneN}_{6} \mathrm{O}_{4}, \mathrm{PP}-=\right.$ diphenyl phosphate). Inorg. Chem. 36, 2784-2790. doi: 10.1021/ic961521j

Bennett, B., and Holz, R. C. (1997). EPR Studies on the mono- and dicobalt(II)substituted forms of the aminopeptidase from aeromonas proteolytica. Insight into the catalytic mechanism of dinuclear hydrolases. J. Am. Chem. Soc. 119, 1923-1933. doi: 10.1021/ja963021v

Benning, M. M., Shim, H., Raushel, F. M., and Holden, H. M. (2001). High resolution X-ray structures of different metal-substituted forms of phosphotriesterase from pseudomonas diminuta. Biochemistry 40, 2712-2722. doi: $10.1021 / \mathrm{bi002661e}$ when the leaving group was changed and thus contributed to a better fundamental understanding of metal-catalyzed phosphate ester hydrolysis.

In contrast to the large amount of data that has been collected on the cleavage of phosphate esters at biomimetic dizinc(II) sites, little attention has been paid to the regeneration of the catalyst. After hydrolysis of the phosphotri-, di- or monoester, the resulting diester, monoester or ortho phosphate will be coordinated in a bridging mode and will bind more strongly to the catalyst as the anionic charge has increased. Ejection of the hydrolysis product would require nucleophilic attack of water on the metal(s). Obviously, the regeneration of the dizinc(II) site is important for catalytic turnover and there is a clear need for future work in this direction.

\section{AUTHOR CONTRIBUTIONS}

The author confirms being the sole contributor of this work and has approved it for publication.
Berg, J. M., Tymoczko, J. L., and Stryer, L. (2010). Biochemistry. 7th edn. New York, NY: W. H. Freeman and Co.

Bím, D., Svobodová, E., Eigner, V., Rulíšek, L., and Hodačová, J. (2016). Copper(II) and zinc(II) complexes of conformationally constrained polyazamacrocycles as efficient catalysts for RNA model substrate cleavage in aqueous solution at physiological pH. Chem. Eur. J. 22, 10426-10437. doi: 10.1002/chem.201601175

Borovik, A. S., Que, L. Jr., Papaefthymiou, V., Muenck, E., Taylor, L. F., and Anderson, O. P. (1988). Heterobimetallic complexes with ( $\mu$-phenoxo)bis $(\mu$ carboxylato) cores. J. Am. Chem. Soc. 110, 1986-1988. doi: 10.1021/ja00214a065

Bosch, S., Comba, P., Gahan, L. R., and Schenk, G. (2014). Dinuclear zinc(II) complexes with hydrogen bond donors as structural and functional phosphatase models. Inorg. Chem. 53, 9036-9051. doi: 10.1021/ic50 09945

Bosch, S., Comba, P., Gahan, L. R., and Schenk, G. (2016). Asymmetric mono- and dinuclear GaIII and $\mathrm{ZnII}$ complexes as models for purple acid phosphatases. J. Inorg. Biochem. 162, 343-355. doi: 10.1016/.j.jinorgbio.2015.12.028

Breslow, R., Huang, D. L., and Anslyn, E. (1989). On the mechanism of action of ribonucleases: dinucleotide cleavage catalyzed by imidazole and zinc(2+). Proc. Natl. Acad. Sci. U.S.A. 86, 1746-1750. doi: 10.1073/pnas.86.6.1746

Brown, J. J., Gahan, L. R., Schöffler, A., Krenske, E. H., and Schenk, G. (2016). Investigation of the identity of the nucleophile initiating the hydrolysis of phosphate esters catalyzed by dinuclear mimics of metallohydrolases. J. Inorg. Biochem. 162, 356-365. doi: 10.1016/j.jinorgbio.2016.02.008

Bunn, S. E., Liu, C. T., Lu, Z. L., Neverov, A. A., and Brown, R. S. (2007). The dinuclear $\mathrm{Zn}$ (II) complex catalyzed cyclization of a series of 2-hydroxypropyl aryl phosphate RNA models: progressive change in mechanism from ratelimiting $\mathrm{P}-\mathrm{O}$ bond cleavage to substrate binding. J. Am. Chem. Soc. 129, 16238-16248. doi: $10.1021 /$ ja076847d

Camargo, T. P., Neves, A., Peralta, R. A., Chaves, C., Maia, E. C. P., LizarazoJaimes, E. H., et al. (2018). Second-sphere effects in dinuclear $\mathrm{Fe}^{\mathrm{III}} \mathrm{Zn}^{\mathrm{II}}$ hydrolase biomimetics: tuning binding and reactivity properties. Inorg. Chem. 57, 187-203. doi: 10.1021/acs.inorgchem.7b02384

Carlsson, H., Haukka, M., and Nordlander, E. (2004). Structural and functional models of the active site of zinc phosphotriesterase. Inorg. Chem. 43, 5681-5687. doi: $10.1021 /$ ic 0354522

Cashikar, A. G., Kumaresan, R., and Rao, N. M. (1997). Biochemical characterization and subcellular localization of the red kidney bean purple acid phosphatase. Plant Physiol. 114, 907-915. doi: 10.1104/pp.114.3.907

Chen, J., Wang, X., Zhu, Y., Lin, J., Yang, X., Li, Y., et al. (2005). An asymmetric dizinc phosphodiesterase model with phenolate and carboxylate bridges. Inorg. Chem. 44, 3422-3430. doi: 10.1021/ic048654m 
Chin, J. (1991). Developing artificial hydrolytic metalloenzymes by a unified mechanistic approach. Acc. Chem. Res. 24, 145-152. doi: 10.1021/ar00005a004

Cleland, W. W., and Hengge, A. C. (2006). Enzymatic mechanisms of phosphate and sulfate transfer. Chem. Rev. 106, 3252-3278. doi: 10.1021/cr050287o

Coleman, F., Hynes, M. J., and Erxleben, A. (2010). Ga(III) complexes as models for the M(III) site of purple acid phosphatase: ligand effects on the hydrolytic reactivity toward bis(2,4-dinitrophenyl)phosphate. Inorg. Chem. 49, 67256733. doi: $10.1021 /$ ic $100722 \mathrm{w}$

Cowan, J. A. (1998). Metal activation of enzymes in nucleic acid biochemistry. Chem. Rev. 98, 1067-1087. doi: 10.1021/cr960436q

Das, B., Daver, H., Pyrkosz-Bulska, M., Gumienna-Kontecka, E., Himo, F., and Nordlander, E. (2018). An unsymmetric ligand with a $\mathrm{N}_{5} \mathrm{O}_{2}$ donor set and its corresponding dizinc complex: a structural and functional phosphoesterase model. Eur. J. Inorg. Chem. 4004-4013. doi: 10.1002/ejic.201701416

Das, B., Daver, H., Pyrkosz-Bulska, M., Persch, E., Barman, S. K., Mukherjee, R., et al. (2014). A dinuclear zinc(II) complex of a new unsymmetric ligand with an $\mathrm{N}_{5} \mathrm{O}_{2}$ donor set; $A$ structural and functional model for the active site of zinc phosphoesterases. J. Inorg. Biochem. 132, 6-17. doi: 10.1016/j.jinorgbio.2013.08.001

Daumann, L. J., Dalle, K. E., Schenk, G., McGeary, R. P., Bernhardt, P. V., Ollis, D. $\mathrm{L}$., et al. (2012). The role of $\mathrm{Zn}-\mathrm{OR}$ and $\mathrm{Zn}-\mathrm{OH}$ nucleophiles and the influence of para-substituents in the reactions of binuclear phosphatase mimetics. Dalton Trans. 41, 1695-1708. doi: 10.1039/C1DT11187F

Daumann, L. J., Marty, L., Schenk, G., and Gahan, L. R. (2013). Asymmetric zinc(II) complexes as functional and structural models for phosphoesterases. Dalton Trans. 42, 9574-9584. doi: 10.1039/C3DT50514F

Daumann, L. J., Schenk, G., Ollis, D. L., and Gahan, L. R. (2014). Spectroscopic and mechanistic studies of dinuclear metallohydrolases and their biomimetic complexes. Dalton Trans. 43, 910-928. doi: 10.1039/c3dt52287c

Daver, H., Das, B., Nordlander, E., and Himo, F. (2016). Theoretical study of phosphodiester hydrolysis and transesterification catalyzed by an unsymmetric biomimetic dizinc complex. Inorg. Chem. 55, 1872-1882. doi: 10.1021 /acs.inorgchem.5b02733

Davies, J. F., Hostomska, Z., Hostomsky, Z., Jordan, S. R., and Matthews, D. A. (1991). Crystal structure of the ribonuclease H domain of HIV-1 reverse transcriptase. Science 252, 88-95. doi: 10.1126/science. 1707186

Desbouis, D., Troitsky, I. P., Belousoff, M. J., Spiccia, L., and Graham, B. (2012). Copper(II), zinc(II) and nickel(II) complexes as nuclease mimetics. Coord. Chem. Rev. 256, 897-937. doi: 10.1016/j.ccr.2011.12.005

Donarski, W. J., Dumas, D. P., Heitmeyer, D. P., Lewis, V. E., and Raushel, F. M. (1989). Structure-activity relationships in the hydrolysis of substrates by the phosphotriesterase from Pseudomonas diminuta. Biochemistry 28, 4650-4655. doi: 10.1021/bi00437a021

Dumas, D. P., Durst, H. D., Landis, W. G., Raushel, F. M., and Wild, J. R. (1990). Purification and properties of the phosphotriesterase for Pseudomonas diminuta. Arch. Biochem. Biophys. 277, 155-159. doi: 10.1016/0003-9861(90)90564-F

Edwards, D. R., Tsang, W.-Y., Neverov, A. A., and Brown, R. S. (2010). On the question of stepwise vs. concerted cleavage of RNA models promoted by a synthetic dinuclear $\mathrm{Zn}(\mathrm{II})$ complex in methanol: implementation of a noncleavable phosphonate probe. Org. Biomol. Chem. 8, 822-827. doi: $10.1039 / \mathrm{B} 918310 \mathrm{H}$

Ely, F., Hadler, K. S., Gahan, L. R., Guddat, L. W., Ollis, D. L., and Schenk, G. (2010). The organophosphate-degrading enzyme from Agrobacterium radiobacter displays mechanistic flexibility for catalysis. Biochem. J. 432, 565573. doi: 10.1042/BJ201054

Ely, F., Hadler, K. S., Mitić, N., Gahan, L. R., Ollis, D. L., Plugis, N. M., et al. (2011). Electronic and geometric structures of the organophosphate-degrading enzyme from Agrobacterium radiobacter (OpdA). J. Biol. Inorg. Chem. 16, 777-787. doi: 10.1007/s00775-011-0779-6

Fan, Y.-B., and Gao, Y.-Q. (2010). Cooperativity between metals, ligands and solvent: a DFT study on the mechanism of a dizinc complexmediated phosphodiester cleavage. Acta Phys. Chim. Sin. 26, 1034-1042. doi: 10.3866/PKU.WHXB20100447

Feng, G., Natale, D., Prabaharan, R., Mareque-Rivas, J. C., and Williams, N. H. (2006). Efficient phosphodiester binding and cleavage by a $\mathrm{Zn}^{\mathrm{II}}$ complex combining hydrogen-bonding interactions and double Lewis acid activation. Angew. Chem. Int. Ed. 45, 7056-7059. doi: 10.1002/anie.200602532
Ferreira, D. E. C., De Almeida, W. B., Neves, A., and Rocha, W. R. (2008). Theoretical investigation of the reaction mechanism for the phosphate diester hydrolysis using an asymmetric dinuclear metal complex as a biomimetic model of the purple acid phosphatase enzyme. Phys. Chem. Chem. Phys. 10, 7039-7046. doi: 10.1039/b809189g

Franklin, S. J. (2001). Lanthanide-mediated DNA hydrolysis. Curr. Opin. Chem. Biol. 5, 201-208. doi: 10.1016/S1367-5931(00)00191-5

Gao, H., Ke, Z., DeYonker, N. J., Wang, J., Xu, H., Mao, Z.-W., et al. (2011). Dinuclear $\mathrm{Zn}$ (II) complex catalyzed phosphodiester cleavage proceeds via a concerted mechanism: a density functional theory study. J. Am. Chem. Soc. 133, 2904-2915. doi: 10.1021/ja106456u

Gellman, S. H., Petter, R., and Breslow, R. (1986). Catalytic hydrolysis of a phosphate triester by tetracoordinated zinc complexes. J. Am. Chem. Soc. 108, 2388-2394. doi: 10.1021/ja00269a041

Guo, N., Zhong, J.-Y., Chen, S.-L., Liu, J.-Q., Min, Q., and Shi, R.-X. (2015). Experimental and theoretical studies of hydrolysis of nerve agent sarin by binuclear zinc biomimetic catalysts. Chem. Phys. 457, 70-77. doi: 10.1016/j.chemphys.2015.05.011

Guo, Z.-F., Yan, H., Lia, Z.-F., and Lu, Z.-L. (2011). Synthesis of mono- and di-[12] $\mathrm{aneN}_{3}$ ligands and study on the catalytic cleavage of RNA model 2-hydroxypropyl-p-nitrophenyl phosphate with their metal complexes. Org. Biomol. Chem. 9, 6788-6796. doi: 10.1039/С1ОB05942D

Hendry, P., and Sargeson, A. M. (1989). Metal ion promoted phosphate ester hydrolysis. Intramolecular attack of coordinated hydroxide ion. J. Am. Chem. Soc. 111, 2521-2527. doi: 10.1021/ja00189a025

Hengge, A. C. (2002). Isotope effects in the study of phosphoryl and sulfuryl transfer reactions. Acc. Chem. Res. 35, 105-112. doi: 10.1021/ar000143q

Hotzelmann, R., Wieghardt, K., Ensling, J., Romstedt, H., Guetlich, P., Bill, E., et al. (1992). Synthesis, crystal structures, Moessbauer, susceptibility, and EPR studies of a series of spin exchange coupled complexes containing the $(\mu$ oxo)bis( $\mu$-acetato)rutheniummetal core and its hydroxo-bridged analog (metal $=$ vanadium, chromium, manganese, iron, cobalt). J. Am. Chem. Soc. 114, 9470-9483. doi: 10.1021/ja00050a028

Humphry, T., Iyer, S., Iranzo, O., Morrow, J. R., Richard, J. P., Paneth, P., et al. (2008). Altered transition state for the reaction of an RNA model catalyzed by a dinuclear Zinc(II) catalyst. J. Am. Chem. Soc. 130, 17858-17866. doi: $10.1021 /$ ja8059864

Iranzo, O., Elmer, T., Richard, J. P., and Morrow, J. R. (2003a). Cooperativity between metal ions in the cleavage of phosphate diesters and RNA by dinuclear $\mathrm{Zn}$ (II) catalysts. Inorg. Chem. 42, 7737-7746. doi: 10.1021/ic030131b

Iranzo, O., Kovalevsky, A. Y., Morrow, J. R., and Richard, J. P. (2003b). Physical and kinetic analysis of the cooperative role of metal ions in catalysis of phosphodiester cleavage by a dinuclear Zn(II) complex. J. Am. Chem. Soc. 125, 1988-1993. doi: 10.1021/ja027728v

Jackson, C. J., Foo, J. L., Kim, H. K., Carr, P. D., Liu, J. W., Salem, G., et al. (2008). In crystallo capture of a Michaelis complex and productbinding modes of a bacterial phosphotriesterase. J. Mol. Biol. 375, 1189-1196. doi: 10.1016/j.jmb.2007.10.061

Jacques, B., Dro, C., Bellemin-Laponnaz, S., Wadepohl, H., and Gade, L. H. (2008). Self-assembly of a cyclic $\mathrm{Zn}_{4} \mathrm{O}_{4}$ tetramer by aerobic oxidation of a bisoxazoline: a molecular "nest" for nucleophilic $\mathrm{OH}^{-}$. Angew. Chem. Int. Ed. 47, 4546-4550. doi: 10.1002/anie.200800870

Jarenmark, M., Csapó, E., Singh, J., Wöckel, S., Farkas, E., Meyer, F., et al. (2010). Unsymmetrical dizinc complexes as models for the active sites of phosphohydrolases. Dalton Trans. 39, 8183-8194. doi: 10.1039/B925563J

Jarenmark, M., Haukka, M., Demeshko, S., Tuczek, F., Zuppiroli, L., Meyer, F., et al. (2011). Synthesis, characterization, and reactivity studies of heterodinuclear complexes modeling active sites in purple acid phosphatases. Inorg. Chem. 50, 3866-3887. doi: 10.1021/ic1020324

Jarenmark, M., Kappen, S., Haukka, M., and Nordlander, E. (2008). Symmetrical and unsymmetrical dizinc complexes as models for the active sites of hydrolytic enzymes. Dalton Trans. 28, 993-996. doi: 10.1039/B713664A

Jones, D. R., Lindoy, L. F., and Sargeson, A. M. (1983). Hydrolysis of phosphate esters bound to cobalt(III). Kinetics and mechanism of intramolecular attack of hydroxide on coordinated 4-nitrophenyl phosphate. J. Am. Chem. Soc. 105, 7327-7336. doi: 10.1021/ja00363a021

Joshi, P., Hussain, N., Ali, S. R., Rishu, and Bhardwaj, V. K. (2018). Enhanced activity of trinuclear $\mathrm{Zn}$ (II) complexes towards phosphate ester bond cleavage 
by introducing three-metal cooperativity. New J. Chem. 42, 2204-2215. doi: $10.1039 / \mathrm{C} 7 \mathrm{NJ} 03759 \mathrm{G}$

Kamerlin, S. C. L., and Wilkie, J. (2007). The role of metal ions in phosphate ester hydrolysis. J. Org. Biomol. Chem. 5, 2098-2108. doi: 10.1039/B701274H

Kim, J., Tsai, P. C., Chen, S. L., Himo, F., Almo, S. C., and Raushel, F. M. (2008). Structure of diethyl phosphate bound to the binuclear metal center of phosphotriesterase. Biochemistry 47, 9497-9504. doi: 10.1021/bi800971v

Kimura, E. (2000). Dimetallic hydrolases and their models. Curr. Opin. Chem. Biol. 4, 207-213. doi: 10.1016/S1367-5931(99)00076-9

Klabunde, T., Sträter, N., Fröhlich, R., Witzel, H., and Krebs, B. (1996). Mechanism of $\mathrm{Fe}(\mathrm{III})-\mathrm{Zn}$ (II) purple acid phosphatase based on crystal structures. J. Mol. Biol. 259, 737-748. doi: 10.1006/jmbi.1996.0354

Klähn, M., Rosta, E., and Warshel, A. (2006). On the mechanism of hydrolysis of phosphate monoesters dianions in solutions and proteins. J. Am. Chem. Soc. 128, 15310-15323. doi: 10.1021/ja065470t

Koike, T., Kajitani, S., Nakamura, I., Kimura, E., and Shiro, M. (1995). The catalytic carboxyester hydrolysis by a new zinc(II) complex with an alcohol-pendant cyclen (1-(2-hydroxyethyl)-1,4,7,10-tetraazacyclododecane): a novel model for indirect activation of the serine nucleophile by zinc(II) in zinc enzymes. J. Am. Chem. Soc. 117, 1210-1219. doi: 10.1021/ja00109a004

Koike, T., and Kimura, E. (1991). Roles of zinc(II) ion in phosphatases. A model study with zinc(II)-macrocyclic polyamine complexes. J. Am. Chem. Soc. 113, 8935-8941. doi: 10.1021/ja00023a048

Korhonen, H., Koivusalo, T., Toivola, S., and Mikkola, S. (2013). There is no universal mechanism for the cleavage of RNA model compounds in the presence of metal ion catalysts. Org. Biomol. Chem. 11, 8324-8339. doi: 10.1039/C3OB41554F

Korhonen, H., Mikkola, S., and Williams, N. H. (2012). The mechanism of cleavage and isomerisation of RNA promoted by an efficient dinuclear $\mathrm{Zn}^{2+}$ complex. Chem. Eur. J. 18, 659-670. doi: 10.1002/chem.201100721

Koval, T., Østergaard, L. H., Lehmbeck, J., Nørgaard, A., Lipovová, P., Dušková, J., et al. (2016). Structural and catalytic properties of S1 nuclease from Aspergillus oryzae responsible for substrate recognition, cleavage, non-specificity, and inhibition. PLOS ONE 11:e0168832. doi: 10.1371/journ al.pone. 0168832

Kuimelis, R. G., and McLaughlin, L. W. (1998). Mechanisms of ribozyme-mediated RNA cleavage. Chem. Rev. 98, 1027-1044. doi: 10.1021/cr960426p

Lad, C., Williams, N. H., and Wolfenden, R. (2002). The rate of hydrolysis of phosphomonoester dianions and the exceptional catalytic proficiencies of protein and inositol phosphatases. Proc. Natl. Acad. Sci. U.S.A. 100, 5607-5610. doi: 10.1073/pnas.0631607100

Lanznaster, M., Neves, A., Bortoluzzi, A. J., Szpoganicz, B., and Schwingel, E. (2002). New $\mathrm{Fe}^{\mathrm{III}} \mathrm{Zn}^{\mathrm{II}}$ complex containing a single terminal $\mathrm{Fe}-\mathrm{O}_{\text {phenolate }}$ bond as a structural and functional model for the active site of red kidney bean purple acid phosphatase. Inorg. Chem. 41, 5641-5643. doi: 10.1021/ic025892d

Le Du, M. H., Lamoure, C., Muller, B. H., Bulgakov, O. V., Lajeunesse, E., Menez, A., et al. (2002). Artificial evolution of an enzyme active site: structural studies of three highly active mutants of Escherichia coli alkaline phosphatase. J. Mol. Biol. 316, 941-953. doi: 10.1006/jmbi.2001.5384

Leivers, M., and Breslow, R. (2001). Concerning two-metal cooperativity in model phosphate hydrolysis. Bioorg. Chem. 29, 345-356. doi: 10.1006/bi oo.2001.1221

Linjalahti, H., Feng, G., Mareque-Rivas, J. C., Mikkola, S., and Williams, N. H. (2008). Cleavage and isomerization of UpU promoted by dinuclear metal ion complexes. J. Am. Chem. Soc. 130, 4232-4233. doi: 10.1021/ja711347w

Liu, C., and Wang, L. (2009). DNA hydrolytic cleavage catalyzed by synthetic multinuclear metallonucleases. Dalton Trans. 2, 227-239. doi: $10.1039 / \mathrm{B} 811616 \mathrm{D}$

Liu, C. T., Melnychuk, S. A., Liu, C., Neverov, A. A., and Brown, R. S. (2009). Cleavage of models for RNA mediated by a diZn(II) complex of bis $\left[1,4-\mathrm{N}_{1}, \mathrm{~N}_{1}{ }^{\prime}\right.$. Cleavage of models for RNA mediated by a diZn(II) complex oCan. J. Chem. 87, 640-649. doi: 10.1139/V09-026

Liu, C. T., Neverov, A. A., and Brown, R. S. (2008a). Enzyme-like acceleration for the hydrolysis of a DNA model promoted by a dinuclear $\mathrm{Zn}$ (II) catalyst in dilute aqueous ethanol. J. Am. Chem. Soc. 130, 13870-13872. doi: 10.1021/j a805801j

Liu, C. T., Neverov, A. A., and Brown, R. S. (2008b). Biomimetic cleavage of RNA models promoted by a dinuclear $\mathrm{Zn}$ (II) complex in ethanol. Greater than 30 $\mathrm{kcal} / \mathrm{mol}$ stabilization of the transition state for cleavage of a phosphate diester J. Am. Chem. Soc. 130, 16711-16720. doi: 10.1021/ja806462x

Livieri, M., Mancin, F., Tonellato, U., and Chin, J. (2004). Multiple functional group cooperation in phosphate diester cleavage promoted by $\mathrm{Zn}$ (II) complexes. Chem. Comm. 40, 2862-2863. doi: 10.1039/B412111B

Lönnberg, H., Strömberg, R., and Williams, A. (2004). Compelling evidence for a stepwise mechanism of the alkaline cyclisation of uridine 3omplexesthan 30 kcalOrg. Biomol. Chem. 2, 2165-2167. doi: 10.1039/B406926A

López-Canut, V., Martí, S., Bertrán, J., Moliner, V., and Tuñón, I. (2009). Theoretical modeling of the reaction mechanism of phosphate monoester hydrolysis in alkaline phosphatase. J. Phys. Chem. B. 113, 7816-7824. doi: 10.1021/jp901444g

Ma, X., Zhang, L., Xia, M., Li, S., Zhang, X., and Zhang, Y. (2017). Mimicking the active sites of organophosphorus hydrolase on the backbone of graphene oxide to destroy nerve agent simulants. ACS Appl. Mater. Interfaces 9, 21089-21093. doi: 10.1021 /acsami.7b07770

Mancin, F., and Tecilla, P. (2007). Zinc(II) complexes as hydrolytic catalysts of phosphate diester cleavage: from model substrates to nucleic acids. New J. Chem. 31, 800-817. doi: 10.1039/b703556j

Massoud, S. S., Ledet, C. C., Junk, T., Bosch, S., Comba, P., Herchel, R., et al. (2016). Dinuclear metal(II)-acetato complexes based on bicompartmental 4-chlorophenolate: syntheses, structures, magnetic properties, DNA interactions and phosphodiester hydrolysis. Dalton Trans. 45, 12933-12950. doi: 10.1039/C6DT02596J

Maxwell, C. I., Mosey, N. I., and Brown, R. S. (2013). DFT computational study of the methanolytic cleavage of DNA and RNA phosphodiester models promoted by the dinuclear $\mathrm{Zn}$ (II) complex of 1,3-bis(1,5,9-triazacyclododec-1yl)propane. J. Am. Chem. Soc. 135, 17209-17222. doi: 10.1021/ja4088264

Menger, F. M., and Ladika, M. (1987). Origin of rate accelerations in an enzyme model: the p-nitrophenyl ester syndrome. J. Am. Chem. Soc. 109, 3145-3146. doi: $10.1021 /$ ja00244a047

Meyer, F. (2006). Clues to dimetallohydrolase mechanisms from studies on pyrazolate-based bioinspired dizinc complexes - Experimental evidence for a functional $\mathrm{Zn}-\mathrm{O}_{2} \mathrm{H}_{3}-\mathrm{Zn}$ motif. Eur. J. Inorg. Chem. 3789-3800. doi: $10.1002 /$ ejic.200600590

Mitić, N., Smith, S. J., Neves, A., Guddat, L. W., Gahan, L. R., and Schenk, G. (2006). The catalytic mechanisms of binuclear metallohydrolases. Chem. Rev. 106, 3338-3363. doi: 10.1021/cr050318f

Mohamed, M. F., and Brown, R. S. (2010). Cleavage of an RNA model catalyzed by dinuclear $\mathrm{Zn}(\mathrm{II})$ complexes containing rate-accelerating pendants. Comparison of the catalytic benefits of H-bonding and hydrophobic substituents. J. Org. Chem. 75, 8471-8477. doi: 10.1021/jo1017316

Mohamed, M. F., Neverov, A. A., and Brown, R. S. (2009). Investigation of the effect of oxy bridging groups in dinuclear $\mathrm{Zn}$ (II) complexes that catalyze the cleavage of a simple phosphate diester RNA analogue. Inorg. Chem. 48, 11425-11433. doi: 10.1021/ic9015965

Montagner, D., Gandin, V., Marzano, C., and Erxleben, A. (2014). Phosphate diester cleavage, DNA interaction and cytotoxic activity of a bimetallic bis(1,4,7-triazacyclononane) zinc complex. Eur. J. Inorg. Chem. 25, 4084-4092. doi: $10.1002 /$ ejic.201402319

Morrow, J. R. (2008). Speed limits for artificial ribonucleases. Comments Inorg. Chem. 29, 169-188. doi: 10.1080/02603590802551801

Neverov, A. A., Liu, C. T., Bunn, S. E., Edwards, D., White, C. J., Melnychuk, S. A., et al. (2008). A simple DNase model system comprising a dinuclear $\mathrm{Zn}$ (II) complex in methanol accelerates the cleavage of a series of methyl aryl phosphate diesters by $10^{11}-10^{13}$. J. Am. Chem. Soc. 130, 6639-6649. doi: 10.1021/ja8006963

Neverov, A. A., Lu, Z.-L., Maxwell, C. I., Mohamed, M. F., White, C. J., Tsang, J. S. W., et al. (2006). Combination of a dinuclear $\mathrm{Zn}^{2+}$ complex and a medium effect exerts a $10^{12}$-fold rate enhancement of cleavage of an RNA and DNA model system. J. Am. Chem. Soc. 128, 16398-16405. doi: 10.1021/ja0651714

Neves, A., Lanznaster, M., Bortoluzzi, A. J., Peralta, R. A., Casellato, A., Castellano, E. E., et al. (2007). An unprecedented Fe $\mathrm{III}^{\mathrm{II}}(\mu-\mathrm{OH}) \mathrm{Zn}^{\mathrm{II}}$ complex that mimics the structural and functional properties of purple acid phosphatases. J. Am. Chem. Soc. 129, 7486-7487. doi: 10.1021/ja10.1021/ic025892d071184l

Oddie, G. W., Schenk, G., Angel, N. Z., Walsh, N., Guddat, L. W., de Jersey, J., et al. (2000). Structure, function, and regulation of tartrate-resistant acid phosphatase. Bone 27, 575-584. doi: 10.1016/S8756-3282(00)00368-9 
O’Donoghue, A., Pyun, S. Y., Yang, M.-Y., Morrow, J. R., and Richard, J. P. (2006). Substrate specificity of an active dinuclear $\mathrm{Zn}$ (II) catalyst for cleavage of RNA analogues and a dinucleoside. J. Am. Chem. Soc. 128, 1615-1621. doi: $10.1021 / \mathrm{ja0} 056167 \mathrm{f}$

Oivanen, M., Kuusela, S., and Lönnberg, H. (1998). Kinetics and mechanisms for the cleavage and isomerization of the phosphodiester bonds of RNA by Brønsted acids and bases. Chem. Rev. 98, 961-990. doi: 10.1021/cr960425x

Pathak, C., Gupta, S. K., Gangwar, M. K., Prakasham, A. P., and Ghosh, P. (2017). Modeling the active site of the purple acid phosphatase enzyme with heterodinuclear mixed valence $\mathrm{M}(\mathrm{II})-\mathrm{Fe}(\mathrm{III})[\mathrm{M}=\mathrm{Zn}, \mathrm{Ni}, \mathrm{Co}$, and $\mathrm{Cu}]$ complexes supported over a $\left[\mathrm{N}_{6} \mathrm{O}\right]$ unsymmetrical ligand. ACS Omega 2, 4737-4750. doi: 10.1021/acsomega.7b00671

Pathak, C., Kumar, D., Gangwar, M. K., Mhatre, D., Roisnel, T., and Ghosh, P. (2018). Heterodinuclear $\mathrm{Zn}$ (II)-Fe(III) and homodinuclear M(II)-M(II) [M $=\mathrm{Zn}$ and $\mathrm{Ni}]$ complexes of a bicompartmental $\left[\mathrm{N}_{6} \mathrm{O}\right]$ ligand as synthetic mimics of the hydrolase family of enzymes. J. Inorg. Biochem. 185, 30-42. doi: 10.1016/j.jinorgbio.2018.04.018

Penkova, L. V., Maciag, A., Rybak-Akimova, E. V., Haukka, M., Pavlenko, V. A., Iskenderov, T. S., et al. (2009). Efficient catalytic phosphate ester cleavage by binuclear zinc(II) pyrazolate complexes as functional models of metallophosphatases. Inorg. Chem. 48, 6960-6971. doi: 10.1021/ic900520j

Peralta, R. A., Bortoluzzi, A. J., de Souza, B., Jovito, R., Xavier, F. R., Couto, R. A. A., et al. (2010). Electronic structure and spectro-structural correlations of $\mathrm{Fe}^{\mathrm{III}} \mathrm{Zn}^{\mathrm{II}}$ biomimetics for purple acid phosphatases: relevance to DNA cleavage and cytotoxic activity. Inorg. Chem. 49, 11421-11438. doi: 10.1 021/ic101433t

Perreault, D. M., and Anslyn, E. V. (1997). Unifying the current data on the mechanism of cleavage-transesterification of RNA. Angew. Chem. Int. Ed. 36, 432-450. doi: 10.1002/anie.199704321

Piovezan, C., Jovito, R., Bortoluzzi, A. J., Terenzi, H., Fischer, F. L., Severino, P. C., et al. (2010). Heterodinuclear $\mathrm{Fe}^{\mathrm{III}} \mathrm{Zn}^{\mathrm{II}}$-bioinspired complex supported on 3-aminopropyl silica. Efficient hydrolysis of phosphate diester bonds. Inorg. Chem. 49, 2580-2582. doi: 10.1021/ic902489j

Raushel, F. M. (2002). Bacterial detoxification of organophosphate nerve agents. Curr. Opin. Microbiol. 5, 288-295. doi: 10.1016/S1369-5274(02)00314-4

Roberts, A. E., Schenk, G., and Gahan, L. R. (2015). A heterodinuclear Fe ${ }^{\mathrm{III}} \mathrm{Zn}^{\mathrm{II}}$ complex as a mimic for purple acid phosphatase with site-specific $\mathrm{Zn}^{\mathrm{II}}$ binding. Eur. J. Inorg. Chem. 3076-3086. doi: 10.1002/ejic.201500351

Rose, A. S., Bradley, A. R, Valasatava, Y., Duarte, J. M, Prlic, A., and Rose, P. W. (2018). NGL viewer: web-based molecular graphics for large complexes. Bioinformatics 34, 3755-3758. doi: 10.1093/bioinformatics/bty419

Sanyal, R., Zhang, X., Kundu, P., Chattopadhyay, T., Zhao, C., Mautner, F. A., et al. (2015). Mechanistic implications in the phosphatase activity of Mannichbased dinuclear zinc complexes with theoretical modeling. Inorg. Chem. 54, 2315-2324. doi: 10.1021/ic502937a

Schenk, G., Gahan, L. R., Carrington, L. E., Mitić, N., Valizadeh, M., Hamilton, S. E., et al. (2005). Phosphate forms an unusual tripodal complex with the Fe-Mn center of sweet potato purple acid phosphatase. Proc. Natl. Acad. Sci. U.S.A. 11, 273-278. doi: 10.1073/pnas.0407239102

Schenk, G., Mitic, N., Hanson, G. R., and Comba, P. (2013). Purple acid phosphatase: a journey into the function and mechanism of a colorful enzyme. Coord. Chem. Rev. 257, 473-482. doi: 10.1016/j.ccr.2012.03.020

Schroeder, G. K., Lad, C., Wyman, P., Williams, N. H., and Wolfenden, R. (2006). The time required for water attack at the phosphorus atom of simple phosphodiesters and of DNA. Proc. Natl. Acad. Sci. U.S.A. 103, 4052-4055. doi: $10.1073 /$ pnas.0510879103

Selmeczi, K., Michel, C., Milet, A., Gautier-Luneau, I., Philouze, C., Pierre, J.-L., et al. (2007). Structural, kinetic, and theoretical studies on models of the zinc-containing phosphodiesterase active center: medium-dependent reaction mechanisms. Chem. Eur. J. 13, 9093-9106. doi: 10.1002/c hem.200700104

Silva, G. A., Amorim, A. L., Souza, B., Gabriel, P., Terenzi, H., Nordlander, E., et al. (2017). Synthesis and characterization of $\mathrm{Fe}^{\mathrm{III}}(\mu-\mathrm{OH}) \mathrm{Zn}^{\mathrm{II}}$ complexes: effects of a second coordination sphere and increase in the chelate ring size on the hydrolysis of a phosphate diester and DNA. Dalton Trans. 46, 11380-11394. doi: 10.1039/C7DT02035J

Smith, S. J., Casellato, A., Hadler, K. S., Mitić, N., Riley, M. J., Bortoluzzi, A. J., et al. (2007). The reaction mechanism of the Ga(III)Zn(II) derivative of uteroferrin and corresponding biomimetics. J. Biol. Inorg. Chem. 12, 1207 1220. doi: 10.1007/s00775-007-0286-y

Song, Y., Zan, J., Yan, H., Lu, Z.-L., and Wang, R. (2012). Steric effects on the catalytic activities of zinc(II) complexes containing [12] $\mathrm{aneN}_{3}$ ligating units in the cleavage of the RNA and DNA model phosphates. Org. Biomol. Chem. 10, 7714-7720. doi: 10.1039/C2OB25624J

Stec, B., Holtz, K. M., and Kantrowitz, E. R. (2000). A revised mechanism for the alkaline phosphatase reaction involving three metal ions. J. Mol. Biol. 299, 1303-1311. doi: 10.1006/jmbi.2000.3799

Steitz, T. A., and Steitz, J. A. (1993). A general two-metal-ion mechanism for catalytic RNA. Proc. Natl. Acad. Sci. U.S.A. 90, 6498-6502. doi: $10.1073 /$ pnas.90.14.6498

Sträter, N., Klabunde, T., Tucker, P., Witzel, H., and Krebs, B. (1995). Crystal structure of a purple acid phosphatase containing a dinuclear Fe(III)-Zn(II) active site. Science 268, 1489-1492. doi: 10.1126/science.7770774.

Tamilselvi, A., and Mugesh, G. (2010). Hydrolysis of organophosphate esters: phosphotriesterase activity of metallo- $\beta$-lactamase and its functional mimics. Chem. Eur. J. 16, 8878-8886. doi: 10.1002/ch em. 201000282

Tsang, W. Y., Edwards, D. R., Melnychuk, S. A., Liu, C. T., Liu, C., Neverov, A. A., et al. (2009). Dinuclear $\mathrm{Zn}$ (II) complex promotes cleavage and isomerization of 2-hydroxypropyl alkyl phosphates by a common cyclic phosphate intermediate. J. Am. Chem. Soc. 131, 4159-4166. doi: 10.1021/ja900525t

Umayal, M., and Mugesh, G. (2011). Metallo- $\beta$-lactamase and phosphotriesterase activities of some zinc(II) complexes. Inorg. Chim. Acta 372, 353-361. doi: 10.1016/j.ica.2011.03.064

Volbeda, A., Lahm, A., Sakiyama, F., and Suck, D. (1991). Crystal structure of Penicillium citrinum P1 nuclease at 2.8 A resolution. EMBO J. 10, 1607-1618.

Wang, X., Ho, R. Y. N., Whiting, A. K., and Que, L. Jr. (1999). Spectroscopic characterization of a ternary phosphatase-substrate-fluoride complex. Mechanistic implications for dinuclear hydrolases. J. Am. Chem. Soc. 121, 9235-9236. doi: 10.1021/ja990732v

Weston, J. (2005). Mode of action of bi- and trinuclear zinc hydrolases and their synthetic analogues. Chem. Rev. 105, 2151-2174. doi: 10.1021/c $\mathrm{r} 020057 \mathrm{z}$

Williams, N. H., Takasaki, B., Wall, M., and Chin, J. (1999). Structure and nuclease activity of simple dinuclear metal complexes: quantitative dissection of the role of metal ions. Acc. Chem. Res. 32, 485-493. doi: 10.1021/AR 9500877

Xia, J., Shi, Y.-,b., Zhang, Y., Miao, Q., and Tang, W.-X. (2003). Deprotonation of zinc(II)-water and $\operatorname{zinc}(\mathrm{II})$-alcohol and nucleophilicity of the resultant zinc(II) hydroxide and zinc(II) alkoxide in double-functionalized complexes: theoretical studies on models for hydrolytic zinc enzymes. Inorg. Chem. 42, 70-77. doi: 10.1021/ic020040z

Xia, M., Zhuo, C., Ma, X., Zhang, X., Sun, H., Zhai, Q., et al. (2017). Assembly of the active center of organophosphorus hydrolase in metal-organic frameworks via rational combination of functional ligands. Chem. Comm. 53, 11302-11305. doi: 10.1039/C7CC06270B

Yang, H., Carr, P. D., McLoughlin, S. Y., Liu, J. W., Horne, I., Qiu, X., et al. (2003). Evolution of an organophosphate-degrading enzyme: a comparison of natural and direct evolution. Protein Eng. Des. Sel. 16, 135-145. doi: 10.1093/proeng/gzg013

Yang, M.-Y., Iranzo, O., Richard, J. P., and Morrow, J. R. (2005). Solvent deuterium isotope effects on phosphodiester cleavage catalyzed by an extraordinarily active $\mathrm{Zn}$ (II) complex. J. Am. Chem. Soc. 127, 1064-1065. doi: $10.1021 / j a 044617 \mathrm{i}$

Yang, M.-Y., Morrow, J. R., and Richard, J. P. (2007). A transition state analog for phosphate diester cleavage catalyzed by a small enzyme-like metal ion complex. Bioorg. Chem. 35, 366-374. doi: 10.1016/j.bioorg.2007.02.003

Yashiro, M., and Kawahara, R. (2004). Molecular design of an acid-base cooperative catalyst for RNA cleavage based on a dizinc complex. J. Biol. Inorg. Chem. 9, 914-921. doi: 10.1007/s00775-004-0596-2

Young, M. J., and Chin, J. (1995). Dinuclear copper(II) complex that hydrolyzes RNA. J. Am. Chem. Soc. 117, 10577-10578. doi: 10.1021/j a00147a022

Yu, Z., and Cowan, J. A. (2018). Metal complexes promoting catalytic cleavage of nucleic acids - biochemical tools and therapeutics. Curr. Opin. Chem. Biol. 43, 37-42. doi: 10.1016/j.cbpa.2017.10.029 
Zalatan, J. G., Catrina, I., Mitchell, R., Grzyska, P. K., O’Brien, P. J., Herschlag, D., et al. (2007). Kinetic isotope effects for alkaline phosphatase reactions: implications for the role of active-site metal ions in catalysis. J. Am. Chem. Soc. 129, 9789-9798. doi: 10.1021/ja072196+

Zhang, X., Xu, X., Xu, H., Zhang, X., Phillips, D. L., and Zhao, C. (2014a). Mechanistic investigation into the cleavage of a phosphomonoester mediated by a symmetrical oxyimine-based macrocyclic zinc(II) complex. ChemPhysChem 15, 1887-1898. doi: 10.1002/cphc.201301216

Zhang, X., Zheng, X., Phillips, D. L., and Zhao, C. (2014b). Mechanistic investigation of the cleavage of phosphodiester catalyzed by a symmetrical oxyimine-based macrocyclic dinuclear zinc complex: a DFT study. Dalton Trans. 43, 16289-16299. doi: 10.1039/c4dt01491j

Zhang, X., Zhu, Y., Zheng, X., Phillips, D. L., and Zhao, C. (2014c). Mechanistic investigation on the cleavage of phosphate monoester catalyzed by unsymmetrical macrocyclic dinuclear complexes: the selection of metal centers and the intrinsic flexibility of the ligand. Inorg. Chem. 53, 3354-3361. doi: $10.1021 /$ ic $402717 \mathrm{x}$

Conflict of Interest Statement: The author declares that the research was conducted in the absence of any commercial or financial relationships that could be construed as a potential conflict of interest.

Copyright (๑) 2019 Erxleben. This is an open-access article distributed under the terms of the Creative Commons Attribution License (CC BY). The use, distribution or reproduction in other forums is permitted, provided the original author $(s)$ and the copyright owner(s) are credited and that the original publication in this journal is cited, in accordance with accepted academic practice. No use, distribution or reproduction is permitted which does not comply with these terms. 